\title{
Biodiversidade e distribuição das diatomáceas (Bacillariophyceae) de sedimentos superficiais nos reservatórios em cascata do rio Paranapanema, SP/PR, Brasil
}

\author{
Luciane Fontana ${ }^{1,2}$ e Denise de Campos Bicudo ${ }^{2,3}$
}

Recebido: 10.07.2012; aceito: 23.11.2012

\begin{abstract}
Biodiversity and distribution of diatoms (Bacillariophyceae) from surface sediments in the cascading reservoirs of Paranapanema river, São Paulo and Paraná States, Brazil). Paper presents the taxonomic survey and distribution of diatoms (class Bacillariophyceae) from the surface sediments of five cascading reservoirs of the Paranapanema river. Samples were dredged from three sampling stations (upstream, middle portion, and close to the dam) of reservoirs. 44 taxa belonging to 22 genera were identified, 23 (52.3\%) of which represent new records for the Paranapanema river basin, four (9.1\%) for the São Paulo State, and two (4.5\%) for the Paraná State. Morphometric data, relevant comments, and local spatial distribution of species in the São Paulo and Paraná States are available. Taxonomic richness was markedly greater in the first reservoir (Jurumirim) and in the sampling station with influence of the Tibagi river. Present work is a pioneer contribution to the country in regard to biodiversity and spatial distribution of diatoms in cascade reservoirs, contributing for future studies on conservation and monitoring of the Paranapanema river basin.
\end{abstract}

Key words: algae, cascade reservoirs, flora, sediment

RESUMO - (Biodiversidade e distribuição das diatomáceas (Bacillariophyceae) de sedimentos superficiais nos reservatórios em cascata do rio Paranapanema, SP/PR, Brasil. O trabalho apresenta os resultados do inventário e da distribuição das diatomáceas da classe Bacillariophyceae de sedimentos superficiais de cinco reservatórios em cascata do rio Paranapanema. Amostras foram coletadas com draga em três locais (montante, região intermediária e lacustre) dos reservatórios. Foram identificados 44 táxons infragenéricos, sendo 23 (52,3\%) novas citações para a bacia do rio Paranapanema, quatro (9,1\%) para o Estado de São Paulo e duas (4,5\%) para o Estado do Paraná. São disponibilizados dados morfométricos, comentários relevantes, distribuição espacial e local de ocorrência das espécies para os Estados de São Paulo e Paraná. A riqueza de espécie foi nitidamente mais elevada no primeiro reservatório da série (Jurumirim) e na estação com influência do rio Tibagi. Este trabalho traz contribuição pioneira para o país no que se refere à biodiversidade e distribuição espacial das diatomáceas em reservatórios em cascata, podendo subsidiar futuros estudos sobre conservação e monitoramento na bacia hidrográfica do rio Paranapanema.

Palavras-chave: algas, flora, represas em cascata, sedimentos

\section{Introdução}

Os sedimentos superficiais acumulam os eventos que ocorreram na bacia de drenagem ao longo de um passado recente, fornecendo uma amostra rica em informações sobre a biodiversidade, uma vez que integra diferentes hábitats (plâncton, perifíton, bentos) ao longo do tempo e inviável de ser obtida a partir de amostras vivas (Bennion 1995). Dessa forma, o estudo das diatomáceas acumuladas no sedimento contribui de forma mais abrangente para o conhecimento da biodiversidade dos ecossistemas aquáticos, podendo subsidiar estudos sobre conservação, bem como sinalizar processos de eutrofização em curso, uma vez que as diatomáceas presentes nesse compartimento vêm sendo amplamente utilizadas como indicadoras

1. Aluna de Mestrado, Programa de Pós-graduação em Biodiversidade Vegetal e Meio Ambiente, Instituto de Botânica, São Paulo, SP, Brasil

2. Instituto de Botânica, Núcleo de Pesquisa em Ecologia, Av. Miguel Stéfano, 3687, 04301-902 São Paulo, SP, Brasil

3. Autor para correspondência: dbicudo@terra.com.br 
de alterações ambientais, como mudanças do $\mathrm{pH}$, nível da água e, principalmente, da eutrofização (Barker et al. 2005).

Pouca atenção vem sendo dada à flora de diatomáceas de reservatórios em cascata, em vista da magnitude dos impactos que esses empreendimentos geram. Sobretudo àqueles que são mais vulneráveis à eutrofização em função do uso inadequado do solo, os quais merecem maior atenção visando à conservação da biodiversidade. Entre os raros estudos realizados em reservatórios em cascata, destacam-se os que abrangeram a comunidade planctônica (Felisberto \& Rodrigues 2005, Silva et al. 2005, Nogueira et al. 2010). Considerando o compartimento dos sedimentos, merece destaque a única contribuição para o Brasil que versa sobre o levantamento das diatomáceas pertencentes às classes Coscinodiscophyceae e Fragilariophyceae dos reservatórios em cascata do rio Paranapanema (Fontana \& Bicudo 2009). As demais contribuições sobre diatomáceas de reservatórios no Brasil contemplaram a flora de diatomáceas de uma dada represa ou tributário em uma série de reservatórios em cascata (Bicudo et al. 1993, Bittencourt-Oliveira 2002), a ecologia de diferentes comunidades de algas, incluindo diatomáceas (Nogueira 2000, BittencourtOliveira 2002, Silva et al. 2005, Nogueira et al. 2010), listagens ou apenas citações de espécies em trabalhos eminentemente ecológicos (Nogueira 2000, Felisberto \& Rodrigues 2005, Silva et al. 2005, Henry et al. 2006, Nogueira et al. 2010). Dada a importância do compartimento sedimentar como acumulador de informações espaço-temporais, existem poucos estudos, sendo a quase totalidade deles com enfoque paleolimnológico e realizados em ecossistemas lênticos do país (e.g., Moro \& Bicudo 1998, Moro et al. 2004, Souza et al. 2007, Costa-Böddeker et al. 2012).

Este trabalho completa o inventário das diatomáceas de sedimentos superficiais dos reservatórios em cascata do rio Paranapanema iniciado por Fontana \& Bicudo (2009). Contribui, pioneiramente, com o levantamento da classe Bacillariophyceae ao longo do rio Paranapanema, buscando ampliar o conhecimento sobre a biodiversidade e distribuição das diatomáceas para os Estados de São Paulo e Paraná, bem como contribui para futuros estudos sobre conservação e biomonitoramento nessa região.

\section{Material e métodos}

O rio Paranapanema tem suas nascentes localizadas na Serra de Paranapiacaba, no Município de Capão Redondo (SP), na área de proteção ambiental da Serra do Mar. Sua bacia hidrográfica localiza-se entre as coordenadas $22-26^{\circ} \mathrm{S}$ e $47-54^{\circ} \mathrm{W}$, estendendo-se pelo sudoeste do Estado de São Paulo e norte do Estado de Paraná. A área drenada é de $100.800 \mathrm{~km}^{2}$, sendo $47 \%$ em território paulista e 53\% no Estado do Paraná. O sistema em cascata de reservatórios do rio Paranapanema é um dos principais tributários do alto rio Paraná. O curso principal do rio, em direção leste-oeste, tem extensão total de $929 \mathrm{~km}$, com $570 \mathrm{~m}$ de desnível, desenvolvendo-se entre as altitudes 809 e $239 \mathrm{~m}$. A declividade relativamente elevada $\left(0,6 \mathrm{~m} \mathrm{~km}^{-1}\right)$, com restritas planícies de inundação, é uma característica importante do rio Paranapanema (Agostinho et al. 1995).

O presente estudo abrangeu os cinco reservatórios mais antigos da série de onze reservatórios em cascata do rio Paranapanema (Jurumirim, Chavantes, Salto Grande, Capivara e Rosana). O alto Paranapanema é referido ao trecho inicial do rio, incluindo as represas de Jurumirim e Chavantes, o médio Paranapanema abrange o trecho compreendido entre Salto Grande e Capivara, e o baixo Paranapanema, a Represa de Rosana.

As amostras de sedimentos superficiais (aproximadamente $10 \mathrm{~cm}$ ) foram coletadas com Draga Van Veen $\left(308 \mathrm{~cm}^{2}\right)$ em três estações de amostragem (regiões à montante, de transição ou próximo à desembocadura do tributário principal e lacustre) dos reservatórios de Jurumirim, Chavantes, Salto Grande e Capivara, e em duas regiões (montante e lacustre) no de Rosana, entre os meses de janeiro e novembro de 2006 (figura 1, tabela 1).

Lâminas permanentes foram preparadas segundo a técnica de oxidação com peróxido de hidrogênio $\left(\mathrm{H}_{2} \mathrm{O}_{2}\right)$ descrita em Battarbee (1986), utilizando Zrax como meio de inclusão. $\mathrm{O}$ exame qualitativo foi, sempre que possível, baseado em análise populacional de forma a representar a variabilidade morfológica dos indivíduos estudados. A análise foi feita por meio de microscópio óptico binocular Zeiss, Axioscop 2 plus, equipado com contraste-de-fase, câmara-clara e com sistema de captura de imagem. Para fins de distribuição geográfica na bacia hidrográfica do rio Paranapanema, foram considerados os táxons citados em literatura desde que passíveis de reidentificação. O sistema de classificação adotado foi o de Medlin \& Kaczmarska (2004) para táxons supra-ordinais e, principalmente, Round et al. (1990) para táxons subordinais. 


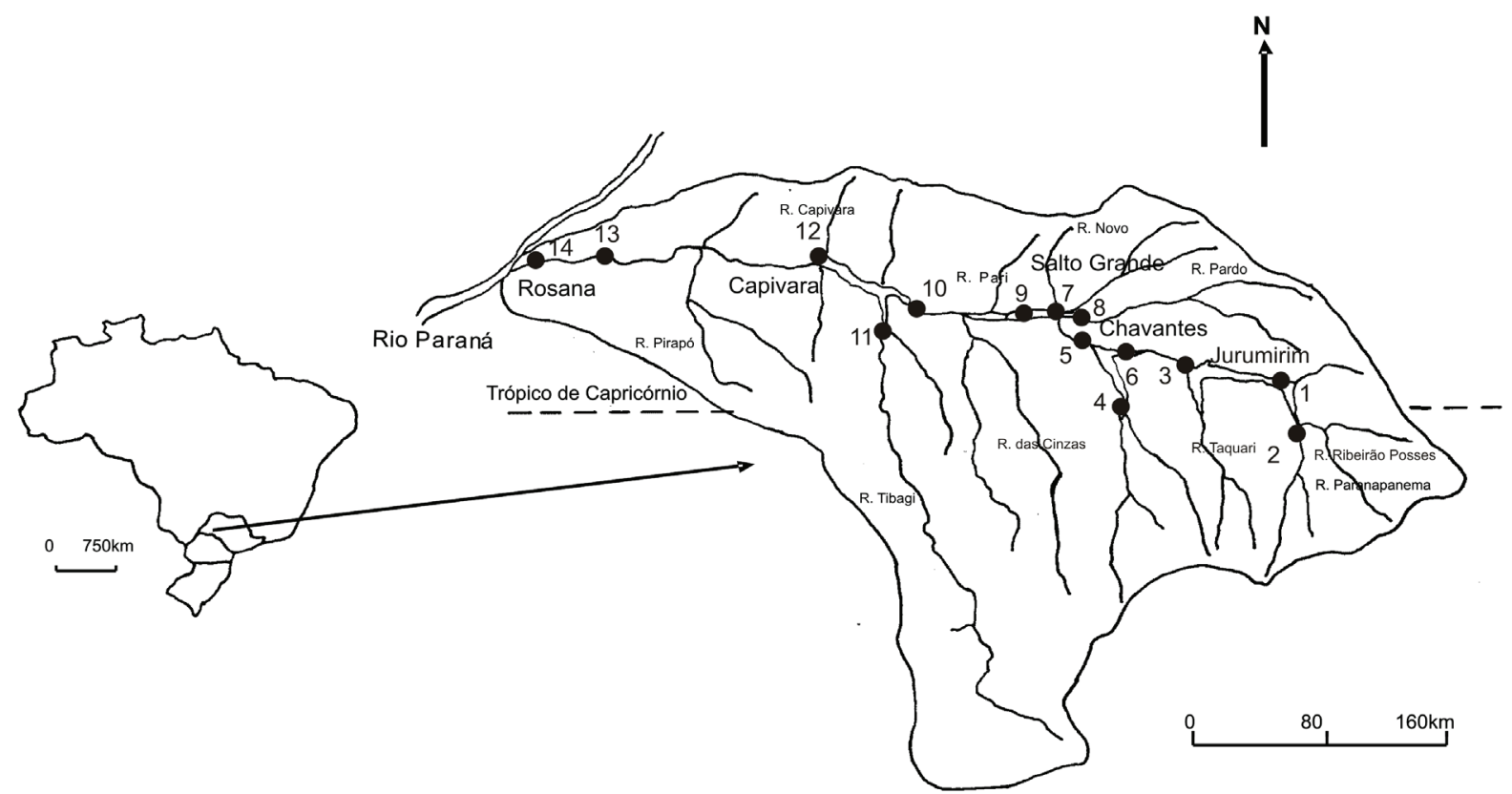

Figura 1. Localização das estações de amostragem nos reservatórios em cascata do rio Paranapanema, SP/PR, Brasil (modificado de Nogueira et al. 2005).

Figure 1. Locations of sampling sites of the cascade reservoirs of the Paranapanema River, São Paulo and Paraná States, Brazil (Adapted from Nogueira et al. 2005).

Tabela 1. Distribuição dos táxons nas estações de amostragens dos reservatórios em cascata do rio Paranapanema, SP/PR, Brasil. Regiões a montante: 1, 4, 7, 10, 13; intermediária: 2, 5, 8, 11; lacustre: 3, 6, 9, 12, 14.

Table 1. Species distribution at the sampling sites of the cascade reservoirs of the Paranapanema river, São Paulo and Paraná States, Brazil. Upstream: 1, 4, 7, 10, 13; central: 2, 5, 8, 11; lacustrine region: 3, 6, 9, 12, 14.

\begin{tabular}{|c|c|c|c|c|c|c|c|c|c|c|c|c|c|c|}
\hline \multirow{2}{*}{$\begin{array}{l}\text { Espécies / Reservatórios } \\
\text { Estações }\end{array}$} & \multicolumn{3}{|c|}{ Jurumirim } & \multicolumn{3}{|c|}{ Chavantes } & \multicolumn{3}{|c|}{ Grande } & \multicolumn{3}{|c|}{ Capivara } & \multicolumn{2}{|c|}{ Rosana } \\
\hline & 1 & 2 & 3 & 4 & 5 & 6 & 7 & 8 & 9 & 10 & 11 & 12 & 13 & 14 \\
\hline Achnanthidium catenatum & & & & & & & & & & & & & $\mathrm{X}$ & $\mathrm{X}$ \\
\hline A. еxiguum & & & $\mathrm{X}$ & & & & $\mathrm{X}$ & & & & $\mathrm{X}$ & & & $\mathrm{X}$ \\
\hline $\begin{array}{l}\text { Amphipleura lindheimerii } \\
\text { var. lindheimerii }\end{array}$ & & & & & & & $\mathrm{X}$ & $\mathrm{X}$ & & & $\mathrm{X}$ & & & $X$ \\
\hline Amphora copulata & & & & & & & & & & $\mathrm{X}$ & $\mathrm{X}$ & & & \\
\hline Capartogramma crucicula & & & & & & & & & & & & & $\mathrm{X}$ & \\
\hline Cocconeis placentula & $\mathrm{X}$ & & $\mathrm{X}$ & $\mathrm{X}$ & & $\mathrm{X}$ & $\mathrm{X}$ & $\mathrm{X}$ & & $\mathrm{X}$ & $\mathrm{X}$ & $\mathrm{X}$ & & \\
\hline Cymbella tropica & & $\mathrm{X}$ & $\mathrm{X}$ & & $\mathrm{X}$ & & & & $\mathrm{X}$ & & & & & \\
\hline Cymbopleura naviculiformis & & & & & & & & & & $\mathrm{X}$ & & & & \\
\hline Diadesmis contenta & & & & & & & & & & & & & $\mathrm{X}$ & $\mathrm{X}$ \\
\hline Encyonema perpusillum & $\mathrm{X}$ & $\mathrm{X}$ & & & $\mathrm{X}$ & & & & $\mathrm{X}$ & $\mathrm{X}$ & $\mathrm{X}$ & & & $\mathrm{X}$ \\
\hline E. silesiacum & $\mathrm{X}$ & & $\mathrm{X}$ & $\mathrm{X}$ & $\mathrm{X}$ & $\mathrm{X}$ & $\mathrm{X}$ & $\mathrm{X}$ & & & $\mathrm{X}$ & $\mathrm{X}$ & $\mathrm{X}$ & \\
\hline Eunotia camelus & & & $\mathrm{X}$ & & & $\mathrm{X}$ & & & & & & & & \\
\hline E. georgii & & & $\mathrm{X}$ & & & $\mathrm{X}$ & & & & & & & & \\
\hline E. monodon & & $\mathrm{X}$ & $\mathrm{X}$ & & & & & & & & & & & \\
\hline E. tridentula var. tridentula & $\mathrm{X}$ & & & & & & & & & & & & & \\
\hline E. rabenhorstii & & $\mathrm{X}$ & $\mathrm{X}$ & & & & & & $\mathrm{X}$ & & & & $\mathrm{X}$ & \\
\hline
\end{tabular}


Tabela 1 (continuação)

\begin{tabular}{|c|c|c|c|c|c|c|c|c|c|c|c|c|c|c|}
\hline \multirow{2}{*}{$\begin{array}{l}\text { Espécies / Reservatórios } \\
\text { Estações }\end{array}$} & \multicolumn{3}{|c|}{ Jurumirim } & \multicolumn{3}{|c|}{ Chavantes } & \multicolumn{3}{|c|}{ Grande } & \multicolumn{3}{|c|}{ Capivara } & \multicolumn{2}{|c|}{ Rosana } \\
\hline & 1 & 2 & 3 & 4 & 5 & 6 & 7 & 8 & 9 & 10 & 11 & 12 & 13 & 14 \\
\hline E. canicula & & $\mathrm{X}$ & $\mathrm{X}$ & $\mathrm{X}$ & $\mathrm{X}$ & $\mathrm{X}$ & $\mathrm{X}$ & $\mathrm{X}$ & $\mathrm{X}$ & $\mathrm{X}$ & $\mathrm{X}$ & $\mathrm{X}$ & & \\
\hline E. zygodon & & $\mathrm{X}$ & $\mathrm{X}$ & $\mathrm{X}$ & & & & $\mathrm{X}$ & $\mathrm{X}$ & & & & & \\
\hline $\begin{array}{l}\text { Frustulia saxônica var. } \\
\text { saxonica }\end{array}$ & & $\mathrm{X}$ & & & & & & & $\mathrm{X}$ & $\mathrm{X}$ & $X$ & & $\mathrm{X}$ & \\
\hline Geissleria aikenensis & $\mathrm{X}$ & & & & & & & & & & & & & \\
\hline Gomphonema acuminatum & $\mathrm{X}$ & $\mathrm{X}$ & $\mathrm{X}$ & & & & & & & & & & & \\
\hline G. gracile & & & & & & & & & & $\mathrm{X}$ & $\mathrm{X}$ & & $\mathrm{X}$ & $\mathrm{X}$ \\
\hline G. lagenula & $\mathrm{X}$ & $\mathrm{X}$ & & & & & & & & & & & & \\
\hline G. laticollum & & $\mathrm{X}$ & & & & & & & & $\mathrm{X}$ & $\mathrm{X}$ & & $\mathrm{X}$ & $\mathrm{X}$ \\
\hline G. parvulum & $\mathrm{X}$ & $\mathrm{X}$ & $\mathrm{X}$ & & & $\mathrm{X}$ & & $X$ & $\mathrm{X}$ & & $X$ & $X$ & & \\
\hline G. subtile & & & & & & & & & & & $\mathrm{X}$ & & & \\
\hline Gyrosigma nodiferum & $\mathrm{X}$ & $\mathrm{X}$ & $\mathrm{X}$ & & & & & & & & & & & \\
\hline Hantzschia amphioxys & & $\mathrm{X}$ & & & $\mathrm{X}$ & $\mathrm{X}$ & $\mathrm{X}$ & & & $\mathrm{X}$ & $X$ & $X$ & & $\mathrm{X}$ \\
\hline Luticola dapalis & $\mathrm{X}$ & & $\mathrm{X}$ & & & $\mathrm{X}$ & $\mathrm{X}$ & $\mathrm{X}$ & & & $\mathrm{X}$ & & & \\
\hline L. cf. goeppertiana & $\mathrm{X}$ & & $\mathrm{X}$ & $\mathrm{X}$ & $\mathrm{X}$ & $\mathrm{X}$ & & & & & & $\mathrm{X}$ & $\mathrm{X}$ & \\
\hline Navicula viridula & & $\mathrm{X}$ & & & & & $\mathrm{X}$ & & & $\mathrm{X}$ & $\mathrm{X}$ & & & \\
\hline Navicula sp. & & $\mathrm{X}$ & $\mathrm{X}$ & & & & & & & & & & $\mathrm{X}$ & \\
\hline Nitzschia amphibia & $\mathrm{X}$ & $\mathrm{X}$ & $\mathrm{X}$ & & & & & & & & & & & \\
\hline N. palea & & $\mathrm{X}$ & & & $\mathrm{X}$ & $\mathrm{X}$ & $\mathrm{X}$ & & & $\mathrm{X}$ & $\mathrm{X}$ & $\mathrm{X}$ & & $\mathrm{X}$ \\
\hline Pinnularia borealis & & $\mathrm{X}$ & & & & & & & & & & & $X$ & $\mathrm{X}$ \\
\hline P. dubitabilis var. dubitabilis & $\mathrm{X}$ & $\mathrm{X}$ & $\mathrm{X}$ & & & & & $\mathrm{X}$ & $\mathrm{X}$ & $\mathrm{X}$ & & $\mathrm{X}$ & & $\mathrm{X}$ \\
\hline P. subgiba & $\mathrm{X}$ & & & & & & & & & & & & & \\
\hline P. trigibboides & $\mathrm{X}$ & & $\mathrm{X}$ & $\mathrm{X}$ & & $\mathrm{X}$ & & $\mathrm{X}$ & $\mathrm{X}$ & & $\mathrm{X}$ & $\mathrm{X}$ & & $\mathrm{X}$ \\
\hline Planothidium lanceolatum & & & $\mathrm{X}$ & & & & $\mathrm{X}$ & $X$ & & & $\mathrm{X}$ & & & \\
\hline P. rostratum & $\mathrm{X}$ & $\mathrm{X}$ & & & & & & & & & & & & \\
\hline Rhopalodia sp. & & & & & & & & & & & & & & $\mathrm{X}$ \\
\hline Total de táxons & 16 & 20 & 20 & 6 & 7 & 11 & 10 & 10 & 9 & 12 & 18 & 9 & 11 & 13 \\
\hline
\end{tabular}

As amostras em lâminas permanentes e material seco encontram-se depositadas no acervo do Herbário Científico do Estado "Maria Eneida P. Kauffmann Fidalgo" do Instituto de Botânica da Secretaria do Meio Ambiente do Estado de São Paulo (SP390881 a SP390894).

\section{Resultados e discussão}

No presente estudo, foram identificados 44 táxons infragenéricos, distribuídos em 22 gêneros e 14 famílias, dos quais 24 espécies $(54,5 \%)$ representam novas citações para a bacia hidrográfica do rio Paranapanema.

Eunotiales

EUNOTIACEAE

Eunotia Ehrenberg
Chave para táxons de Eunotia

1. Margem dorsal convexa sem ou com uma ondulação mediana pronunciada

2. Margem dorsal convexa com uma ondulação.... E. rabenhorstii

2. Margem dorsal convexa sem ondulação

3. Extremidades subcapitadas ............ E. monodon

3. Extremidades atenuado-arredondadas E. canicula

1. Margem dorsal convexa com duas ou mais ondulações

4. Margem dorsal convexa com duas ondulações proeminentes

5. Extremidades cuneado-arredondadas E. zygodon

5. Extremidades atenuado-arredondadas .... E. camelus 
4. Margem dorsal convexa com três ou mais ondulações

6. Margem dorsal com três ondulações .... E. tridentula var. tridentula

6. Margem dorsal com 8-9 ondulações ... E. georgii

Eunotia camelus Ehrenberg, Abh. König. Akad. Wiss. Berl. p. 413, pl. 2(1), fig. 1. 1843.

Figuras 2-3

Valvas com margem dorsal convexa, com duas ondulações medianas, presença de leve depressão em cada ondulação, margem ventral côncava; extremidades atenuado-arredondadas, fletidas para a margem dorsal, nódulos terminais nas extremidades, de difícil visualização; estrias paralelas no centro a radiadas nas extremidades. Medidas: $36,0-39,5 \mu \mathrm{m}$ compr., 6,2-7,5 $\mu \mathrm{m}$ larg., estrias 8-10 em $10 \mu \mathrm{m}$.

As ondulações na margem dorsal podem variar de duas a quatro (Schmidt 1874-1959). No presente estudo foram encontrados exemplares com duas ondulações e que se assemelham às populações encontradas para ambientes lacustres na região Sul do Brasil (Tremarin et al. 2008, Bicca et al. 2011). Trata-se de uma espécie comumente reportada nos Estados de São Paulo e Rio de Janeiro (região Sudeste), Goiás e Distrito Federal (região Centro-Oeste), Paraná e Rio Grande do Sul (região Sul) (Eskinazi-Leça et al. 2012). Para os Estados de Paraná e São Paulo, destaca-se apenas uma contribuição que apresentou material passível de reidentificação (Silva et al. 2010). É a primeira ocorrência da espécie para a bacia do rio Paranapanema, ocorrendo apenas na região lacustre dos reservatórios de Jurumirim e de Chavantes, em $14 \%$ das estações de amostragem (tabela 1 ).

Material examinado: BRASIL. SÃo PaUlo: rio Paranapanema, Reservatório de Jurumirim, sedimento, 24-XI-2006, L. Fontana s.n. (SP390883); Divisa PARANÁ/São PAULO: rio Paranapanema, Reservatório de Chavantes, sedimento, 19-IV-2006, L. Fontana s.n. (SP390886).

Eunotia canicula Furey, Lowe et Johansen. Bibliotheca Diatomologica. v.56, p. 1-34, pl. 22-46, figs. 39-46. 2011.

Figuras 9-10

Valvas com margem dorsal convexa, destituída de ondulações, margem ventral reta a suavemente côncava; extremidades afiladas, sub-rostradas, ápices acuminado-arredondados, destacados do corpo valvar; nódulos terminais nas extremidades, ventrais, de fácil visualização; estrias conspícuas, paralelas a levemente radiadas nas extremidades. Medidas: 23,2-25,0 $\mu \mathrm{m}$ compr., 3,5-5,2 $\mu \mathrm{m}$ larg., estrias 16-22 em $10 \mu \mathrm{m}$.

Os materiais analisados concordam quase que plenamente com a descrição do material-tipo de Eunotia canicula Furey, Lowe \& Johansen, diferindo apenas pelo número um pouco maior de estrias do que no tipo (14-15 em $10 \mu \mathrm{m})$. Esta espécie é bem semelhante a Eunotia incisa Smith ex Gregory, diferindo pelo ápice mais destacado do corpo valvar na segunda espécie, bem como pelas valvas mais estreitas e nódulos terminais mais próximos dos ápices em E. canicula (Furey 2011).

Esta é a primeira citação da espécie para os Estados de São Paulo e Paraná, bem como a primeira ocorrência do táxon para a bacia do rio Paranapanema, onde ocorreu nos reservatórios de Jurumirim, Chavantes, Salto Grande e Capivara (tabela 1), distribuindo-se em 79\% das estações de amostragem.

Material examinado: BRASIL. S̃̃o PAULO: rio Paranapanema, Reservatório de Jurumirim, sedimento, 24-XI-2006, L. Fontana s.n. (SP390882, SP390883); Divisa Paraná/São PaUlo: rio Paranapanema, Reservatório de Chavantes, sedimento, 19-IV-2006, L. Fontana s.n. (SP390884, SP390885, SP390886), Reservatório de Salto Grande, sedimento, 17-I-2006, L. Fontana s.n. (SP390887, SP390888, SP390889), Reservatório de Capivara, sedimento, 17-I-2006, L. Fontana s.n. (SP390890, SP390891, SP390892).

Eunotia georgii Metzeltin \& Lange-Bertalot, Icon. Diat. 5: 61, pl. 41, fig. 1-7, pl. 42, fig. 7-8. 1998.

Figura 4

Valvas com margem dorsal convexa, presença de 7-8 ondulações com cristas arredondadas, margem ventral levemente côncava; extremidades atenuado-arredondadas, nódulos terminais ventrais, de difícil visualização; estrias paralelas na região mediana da valva, tornando-se radiadas em direção às extremidades. Medidas: 50,5-52,7 $\mu \mathrm{m}$ compr., 6,3-9,8 $\mu \mathrm{m}$ larg., estrias $10 \mathrm{em} 10 \mu \mathrm{m}$.

Conforme Metzeltin \& Lange-Bertalot (1998), Eunotia georgii Metzeltin \& Lange-Bertalot assemelha-se a E. serra Ehrenberg da qual difere pelo maior número de ondulações e menor largura valvar $(7-10 \mu \mathrm{m})$. Ainda, E. acuticrenulata Metzeltin \& Lange-Bertalot difere pelas ondulações com cristas mais acuminadas e não arredondadas como em E. georgii Metzeltin \& Lange-Bertalot (Metzeltin \& Lange-Bertalot 2007). 

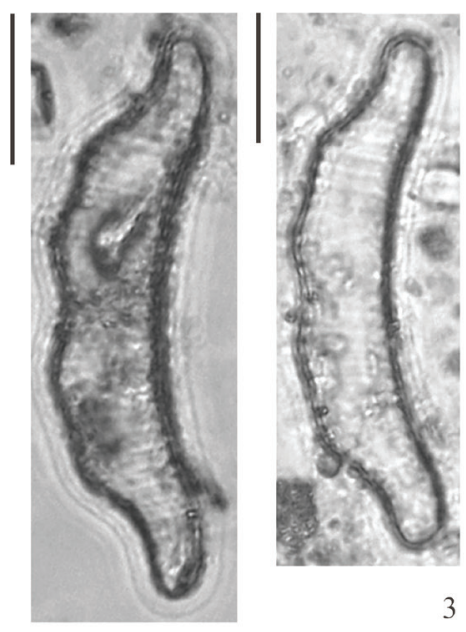

2
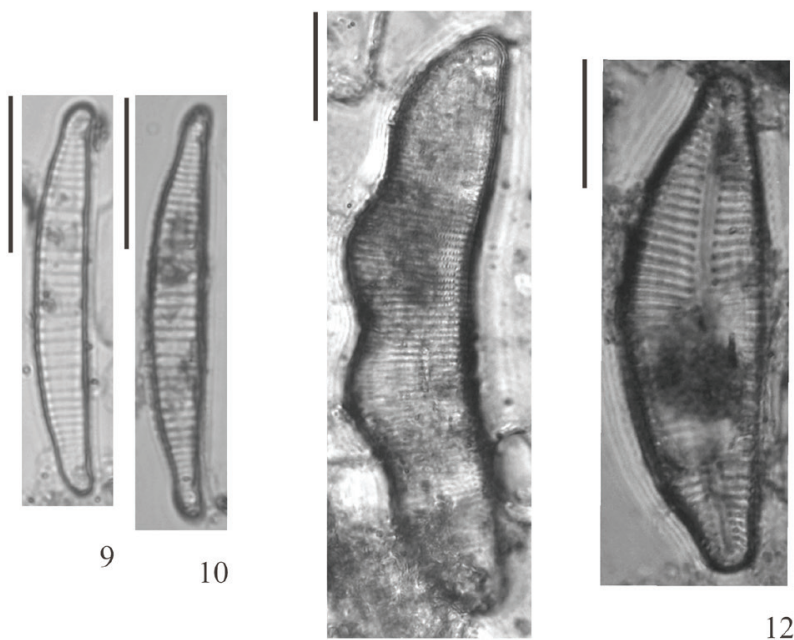

12

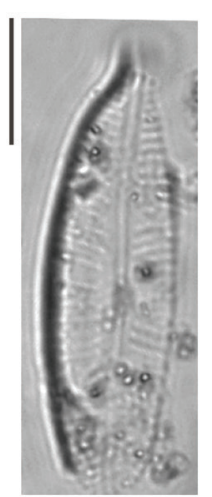

13

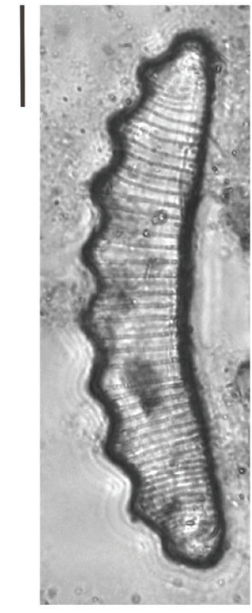

4

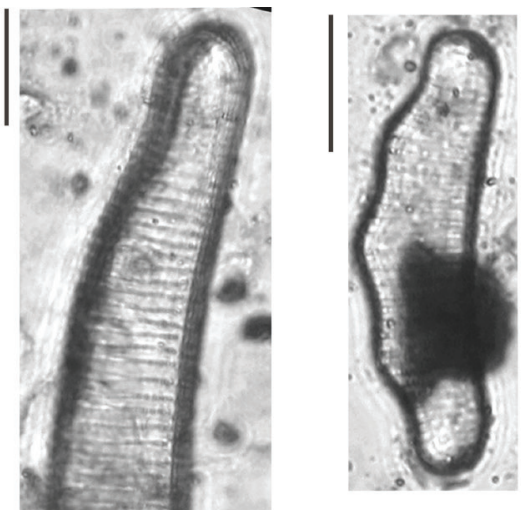

6

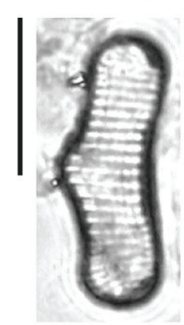

7

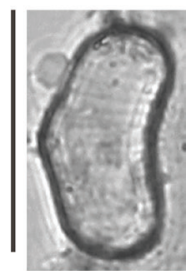

8

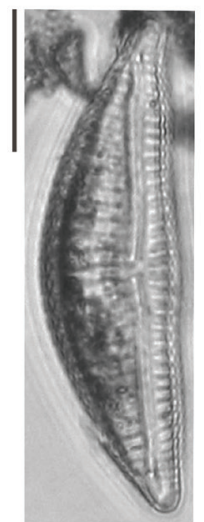

18

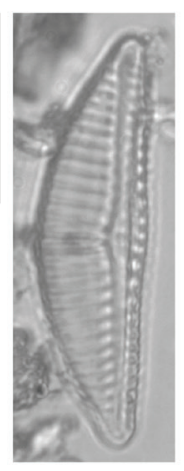

17

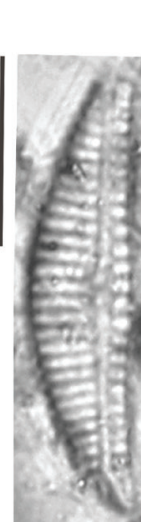

18
19

Figuras 2-19. Representantes da Classe Bacillariophyceae. 2-3. Eunotia camelus Ehrenberg. 4. Eunotia georgii Metzeltin \& LangeBertalot. 5. Eunotia monodon Ehrenberg. 6. Eunotia tridentula Ehrenberg var. tridentula. 7-8. Eunotia rabenhorstii Cleve \& Grunow. 9-10. Eunotia canicula Furey, Lowe et Johansen. 11. Eunotia zygodon Ehrenberg. 12. Cymbella tropica Krammer. 13. Cymbopleura naviculiformis (Auerswald ex. Heiberg) Krammer. 14-15. Encyonema perpusillum (Cleve) Mann. 16-19. Encyonema silesiacum (Bleisch) Mann. Barra da escala $=10 \mu \mathrm{m}$.

Figures 2-19. Taxa of Bacillariophyceae. 2-3. Eunotia camelus Ehrenberg. 4. Eunotia georgii Metzeltin \& Lange-Bertalot. 5. Eunotia monodon Ehrenberg. 6. Eunotia tridentula Ehrenberg var. tridentula. 7-8. Eunotia rabenhorstii Cleve \& Grunow. 9-10. Eunotia canicula Furey, Lowe et Johansen. 11. Eunotia zygodon Ehrenberg. 12. Cymbella tropica Krammer. 13. Cymbopleura naviculiformis (Auerswald ex Heiberg) Krammer. 14-15. Encyonema perpusillum (Cleve) Mann. 16-19. Encyonema silesiacum (Bleisch) Mann. Scale bar = $10 \mu \mathrm{m}$. 
A espécie já foi documentada para as regiões Norte (Amazonas), Centro-Oeste (Distrito Federal) e Sudeste (São Paulo), conforme Eskinazi-Leça et al. (2012). Particularmente para os Estados de São Paulo e Paraná, não foi encontrado nenhum trabalho com material passível de reindentificação. Assim sendo, trata-se da primeira citação comprovada da espécie para o Estado de São Paulo e, por conseguinte, para a bacia do rio Paranapanema, onde foi encontrada no Reservatório de Jurumirim, ocorrendo em 21\% das estações de amostragem.

Material examinado: BRASIL. São PAUlo: rio Paranapanema, Reservatório de Jurumirim, sedimento, 24-XI-2006, L. Fontana s.n. (SP390882, SP390883, SP390884).

Eunotia monodon Ehrenberg, Abh. König. Akad. Wiss. Berl. 1: 414, pl. 2(5), fig. 7, pl. 3(3), fig. 3. 1843.

Figura 5

Valvas com margem dorsal convexa, margem ventral côncava; extremidades subcapitadas, nódulos terminais nas extremidades; estrias conspícuas, paralelas a radiadas em direção às extremidades. Medidas: 84,0-92,7 $\mu \mathrm{m}$ compr., 9,9-13,0 $\mu \mathrm{m}$ larg., estrias 9 em $10 \mu \mathrm{m}$.

Ehrenberg (1843) apresentou duas ilustrações diferentes sob o mesmo epíteto específico, o que originou a atual confusão taxonômica da espécie. Eunotia monodon Ehrenberg difere de E. maior (W. Smith) Rabenhorst principalmente pela margem dorsal convexa e não paralela à margem ventral, extremidades retas, não fletidas (Patrick \& Reimer 1966). Os exemplares do rio Paranapanema foram identificados com base em uma das figuras propostas como tipo por Ehrenberg (1843: pl. 2/5, fig. 7) e seguindo a recomendação de Patrick \& Reimer (1966).

A espécie tem sido amplamente reportada no Brasil, nas regiões Centro-Oeste, Sudeste e Sul (Eskinazi-Leça et al. 2012). Particularmente para o Estado do Paraná existem muitos trabalhos que a reportaram (ex. Lozovei \& Luz 1976, Ludwig \& Flôres 1995, Fürstenberger \& Valente-Moreira 2000, Procopiak et al. 2006, Faria et al. 2010). Para a área de estudo, a espécie já foi citada por Bittencourt-Oliveira (2002) para o rio Tibagi, sendo neste estudo encontrada no Reservatório de Jurumirim, ocorrendo em 14\% das estações de amostragem (tabela 1).

Material examinado: BRASIL. São PaUlo: rio Paranapanema, Reservatório de Jurumirim, sedimento, 24-XI-2006, L. Fontana s.n. (SP390882, SP390883).
Eunotia rabenhorstii Cleve \& Grunow, in Van Heurck. Syn. Diat. Belg. pl. 35, fig. 12B. 1880-1881. Figuras 7-8

Valvas com margem dorsal convexa, com uma ondulação mediana pronunciada, margem ventral côncava a levemente côncava; extremidades amplamente arredondadas, nódulos terminais próximos às extremidades ventrais; estrias paralelas a radiadas em direção às extremidades da valva. Medidas: 9,9-17,7 $\mu \mathrm{m}$ compr., 4,9-5,7 $\mu \mathrm{m}$ larg., estrias 13-14 em $10 \mu \mathrm{m}$.

Apesar da ausência de descrição do material-tipo e da ilustração de baixa qualidade do iconotipo em Van Heurck (1880-1881), a espécie é caracterizada pela presença de uma ondulação mediana na margem dorsal e tem sido amplamente reportada em literatura. No Brasil, é comumente reportada na região Sul (ex. Procopiak et al. 2006, Faria et. al. 2010, Bicca et al. 2011, Eskinazi-Leça et al. 2012) e Centro-Oeste (Eskinazi-Leça et al. 2012). Para o Estado de São Paulo não foram encontrados registros da espécie. Particularmente para a bacia do rio Paranapanema, trata-se da primeira citação, sendo encontrada em 29\% das estações de amostragem e nos reservatórios Jurumirim, Salto Grande e Rosana (tabela 1).

Material examinado: BRASIL. São PAUlo: rio Paranapanema, Reservatório de Jurumirim, sedimento, 24-XI-2006, L. Fontana s.n. (SP390882, SP390883); Divisa Paraná/ São Paulo: rio Paranapanema, Reservatório de Salto Grande, sedimento, 17-I-2006, L. Fontana s.n. (SP390889); Reservatório de Rosana, sedimento, 8-VI-2006, L. Fontana s.n. (SP390893).

Eunotia tridentula Ehrenberg var. tridentula, In Abhandlugen der königlichen Akademie der Wissennschaften zu Berlin. 184. p. 414, pl. 2, fig. 14. 1843.

Figura 6

Valvas com margem dorsal convexa, com três ondulações, margem ventral levemente côncava; extremidades amplamente arredondadas, levemente direcionadas para a margem dorsal, nódulos terminais próximos à região ventral da valva; estrias paralelas a levemente radiadas em direção às extremidades. Medidas: 30,0-33,5 $\mu \mathrm{m}$ compr., 7,4-8,5 $\mu \mathrm{m}$ larg., estrias $10 \mathrm{em} 10 \mu \mathrm{m}$.

Trata-se de uma espécie amplamente reportada para o Estado do Paraná como E. pyramidata Hustedt var. pyramidata (ex. Ludwig et al. 2005, 
Tremarin et al. 2008, Faria et al. 2010), que é considerada sinônimo de E. tridentula Ehr. (Metzeltin \& Lange-Bertalot 1998). Conforme Eskinazi-Leça et al. (2012), também há registros nos Estados do Rio de Janeiro (região Sudeste) e Rio Grande do Sul (região Sul). Neste estudo, foi encontrada à montante do Reservatório de Jurumirim, ocorrendo em 7\% das estações de amostragem (tabela 1). É a primeira ocorrência da espécie para o Estado de São Paulo e, mais especificamente, para a bacia hidrográfica do rio Paranapanema.

Material examinado: BRASIL. São PAUlo: rio Paranapanema, Reservatório de Jurumirim, sedimento, 24-XI-2006, L. Fontana s.n. (SP390881).

Eunotia zygodon Ehrenberg, Phys. Abh. Akad. Wissen. Berl. p.415, pl. 2 (1), fig. 6. 1843. Figura 11

Valvas com margem dorsal convexa, com duas ondulações medianas pronunciadas, margem ventral levemente côncava; extremidades cuneado-arredondadas, nódulos terminais nas extremidades ventrais, de difícil visualização; estrias paralelas a levemente radiadas em direção às extremidades. Medidas: 39,6-54,7 $\mu \mathrm{m}$ compr., 9,2-10,3 $\mu \mathrm{m}$ larg., estrias $15 \mathrm{em} 10 \mu \mathrm{m}$.

Metzeltin \& Lange-Bertalot (1998) diferem E. zygodon Ehrenberg de E. yanomami Metzeltin \& Lange-Bertalot pelos menores valores das valvas (comprimento e largura) e, particularmente, pelas estrias mais espaçadas entre si. Todavia, os autores mencionaram a necessidade de mais estudos uma vez que as duas espécies são fortemente relacionadas. Eunotia zygodon assemelha-se à E. anamargaritae Metzeltin \& Lange-Bertalot, diferindo desta em relação ao comprimento valvar e à presença de ondulações mais proeminentes (menos achatadas) (Metzeltin \& Lange-Bertalot 1998).

A população analisada assemelha-se à encontrada nos Igarapés da Amazônia Central (Ferrari et al. 2007), porém os autores registraram maior espectro de variação morfológica. A espécie tem ampla distribuição geográfica no Brasil (regiões Norte, Centro-Oeste, Sudeste e Sul), conforme Silva et al. (2011) e Eskinazi-Leça et al. (2012). Especialmente para o Estado do Paraná destacam-se alguns trabalhos que a documentaram (Fürstenberger \& Valente-Moreira 2000, Tremarin et al. 2008). Com relação à distribuição na área deste estudo, o táxon já foi reportado para o rio Tibagi por Bittencourt-Oliveira (2002). Neste estudo, distribuiu-se nos reservatórios de Jurumirim, Chavantes e de Salto Grande, ocorrendo em 36\% das estações de amostragem (tabela 1).

Material examinado: BRASIL. São PAULO: rio Paranapanema, Reservatório de Jurumirim, sedimento, 24-XI-2006, L. Fontana s.n. (SP390882, SP390883); Divisa Paraná/São Paulo: rio Paranapanema, Reservatório de Chavantes, sedimento, 19-IV-2006, L. Fontana s.n. (SP390884); Reservatório de Salto Grande, sedimento, 17-I-2006, L. Fontana s.n. (SP390888, SP390889).

\section{CYMBELLALES \\ CYMBELLACEAE Cymbella C. Agardh}

Cymbella tropica Krammer, in H. Lange-Bertalot. Diatoms of Europe. 3: 61, 164, pl. 44, fig. 1-10. 2002.

Figura 12

Valvas dorsiventrais, margens dorsal e ventral convexas; extremidades rostradas, ápice arredondado, área axial linear, acompanhando a dorsiventralidade da valva; estrias radiadas na região mediana da valva, estigma isolado, distinto, localizado na extremidade da estria mediana, de difícil visualização. Medidas: 31,0-38,2 $\mu \mathrm{m}$ compr., 9,5-11,7 $\mu \mathrm{m}$ larg., estrias 12 em $10 \mu \mathrm{m}$.

Cymbella tropica Krammer difere do complexo C. turgidula Grunow principalmente pela menor largura da valva, menor razão $\mathrm{C} / \mathrm{L}$ e presença de apenas um estigma (Krammer 2002).

Não foi encontrada citação desta espécie para o Estado do Paraná. Para o Estado de São Paulo há registros em Marquadart (2012). É a primeira citação da espécie para a bacia do rio Paranapanema, sendo encontrada nos reservatórios de Jurumirim, Chavantes e Capivara, ocorrendo em $36 \%$ das estações de amostragem (tabela 1).

Material examinado: BRASIL. São Paulo: rio Paranapanema, Reservatório de Jurumirim, sedimento, 24-XI-2006, L. Fontana s.n. (SP390882, SP390883); Divisa Paraná/São Paulo: rio Paranapanema, Reservatório de Chavantes, sedimento, 19-IV-2006, L. Fontana s.n. (SP390885); Reservatório de Capivara, sedimento, 17-I-2006, L. Fontana s.n. (SP390890, SP390892).

\section{Cymbopleura (Krammer) Krammer}

Cymbopleura naviculiformis (Auerswald ex Heiberg) Krammer, in Lange-Bertalot. Diatoms of Europe. 4: 56. 2003.

Figura 13 
Valvas dorsiventrais, margens dorsal e ventral convexas, extremidades subcapitadas, área axial linear, área central elíptica, irregular, estigma ausente; estrias curvado-radiadas em toda a extensão valvar, interestria maior do que a estria na região mediana da valva. Medidas: 35,4 $\mu \mathrm{m}$ compr., 11,2 $\mu \mathrm{m}$ larg., estrias 9 em $10 \mu \mathrm{m}$.

Cymbopleura naviculiformis (Auerswald ex Heiberg) Krammer difere de C. amphicephala Näegeli pelo maior comprimento valvar, bem como pela área central mais pronunciada e espessada (Krammer 2003). Apesar da valva incompleta, o material do rio Paranapanema foi facilmente identificado, concordando plenamente com o tipo da espécie em Krammer (2003) e assemelhando-se aos exemplares ilustrados por Kulikovskiy et al. (2009) para a Mongolia.

Há registros de ocorrência desta espécie nas regiões Centro-Oeste (Goiás e Distrito Federal) e Sudeste (São Paulo) do Brasil (Eskinazi-Leça et al. 2012). Para o Estado de São Paulo foram encontradas apenas quatro citações da espécie passíveis de reidentificação (Ludwig 1996, Moutinho et al. 2007, Bere \& Tundisi 2010, Marquardt 2012); e, para o Estado do Paraná, apenas uma (Bertolli et al. 2010). É a primeira citação da espécie para a bacia do rio Paranapanema, onde ocorreu apenas à montante do Reservatório de Capivara, distribuindo-se em 7\% das estações de amostragem (tabela 1).

Material examinado: BRASIL. Divisa Paraná/São PAUlo: rio Para-napanema, Reservatório de Capivara, sedimento, 17-I-2006, L. Fontana s.n. (SP390890).

\section{Encyonema Kützing}

Chave para táxons de Encyonema

1. Valvas com dorsiventralidade pouco acentuada ..... E. perpusillum

1. Valvas com dorsiventralidade acentuada ... E. silesiacum

Encyonema perpusillum (Cleve) Mann, in Round, Crawford \& Mann. The Diatoms, p. 666. 1990. Figuras 14-15

Valvas com dorsiventralidade pouco acentuada, margem dorsal convexa, margem ventral levemente convexa, extremidades sub-rostradas, arredondadas, área axial linear, estreita, estigmóide na região mediana dorsal, de difícil visualização, rafe filiforme; estrias paralelas a suavemente radiadas. Medidas: 18,2-20,7 $\mu \mathrm{m}$ compr., 4,3-6,0 $\mu \mathrm{m}$ larg., estrias $8 \mathrm{em}$ $10 \mu \mathrm{m}$.

Esta espécie é facilmente identificada pela dorsiventralidade pouco acentuada da valva e pela extremidade valvar levemente arredondada. O material do presente trabalho assemelha-se à população de diatomáceas perifíticas dos Arroios Sampaio no Rio Grande do Sul, sobretudo, em relação às métricas valvares (Oliveira et al. 2001). Tem sido amplamente reportada para a região Sul do país (ex. Rodrigues 1991, Brassac et al. 1999, Fürstenberger \& Valente-Moreira 2000, Oliveira et al. 2001); e para o Estado de São Paulo foi registrada na Reserva Biológica de Paranapiacaba (Bicudo et al. 2009). $\mathrm{Na}$ área de estudo, foi identificada como Cymbella perpusilla var. perpusilla por Bicudo et al. (1993) para o Reservatório de Rosana; e, neste estudo, distribuiu-se nos reservatórios de Jurumirim, Chavantes, Salto Grande, Capivara e Rosana, ocorrendo em 50\% das estações de amostragem (tabela 1).

Material examinado: BRASIL. São PAUlo: rio Paranapanema, Reservatório de Jurumirim, sedimento, 24-XI-2006, L. Fontana s.n. (SP390881); Divisa Paraná/São Paulo: rio Paranapanema: Reservatório de Chavantes, sedimento, 19-IV-2006, L. Fontana s.n. (SP390885); Reservatório de Salto Grande, sedimento, 17-I-2006, L. Fontana s.n. (SP390889); Reservatório de Capivara, sedimento, 17-I-2006, L. Fontana s.n. (SP390890, SP390891); Reservatório de Rosana, sedimento, 8-VI-2006, L. Fontana s.n. (SP390894).

Encyonema silesiacum (Bleisch) Mann, in Round, Crawford \& Mann. The Diatoms. p.667. 1990.

Figuras 16-19

Valvas dorsiventrais, margem dorsal fortemente convexa, margem ventral reta, com leve intumescimento central, extremidades cuneadas, retas a levemente fletidas para a margem ventral, área axial linear, estreita, área central reduzida, estigmóide mediano dorsal, de difícil visualização, rafe filiforme; estrias dorsais paralelas a levemente radiadas em direção às extremidades, estrias ventrais levemente radiadas a convergentes. Medidas: 21,3-36,2 $\mu \mathrm{m}$ compr., 4,9-12,1 $\mu \mathrm{m}$ larg., estrias $11 \mathrm{em} 10 \mu \mathrm{m}$, ca. 24 aréolas em $10 \mu \mathrm{m}$.

Encyonema silesiacum (Bleisch) Mann pode ser facilmente confundida com E. minutum (Hilse) D.G. Mann, da qual se separa por apresentar dimensões 
usualmente maiores, areolação menos delicada e visível em microscopia óptica (30-38 aréolas em $10 \mu \mathrm{m}$ em E. minutum) e pelo estigmóide mais conspícuo. Conforme Marquardt (2012), a areolação é a característica que mais separa E. minutum (Hilse) D.G. Mann dos exemplares menores de E. silesiacum (Bleisch) Mann. Os exemplares maiores desta espécie também podem ser confundidos com $E$. neomesianum Krammer, diferindo pelas margem ventral mais intumescida e pelas extremidades atenuadas e não arredondadas como em E. silesiacum (Bleisch) Mann (Marquardt 2012).

Trata-se de uma espécie amplamente distribuída no Brasil nas regiões Norte, Centro-Oeste, Sudeste e Sul (Eskinazi-Leça et al. 2012). Os trabalhos que incluem material passível de reidentificação são raros, destacando-se dois para o Estado de São Paulo (Moutinho et al.2007, Marquardt 2012) e três para o Estado do Paraná (Bertolli et al. 2010, Torgan et al. 2009, Silva et al. 2010). Para a área de estudo foi identificada como Cymbella silesiaca Bleisch por Bicudo et al. (1993) e Bittencourt-Oliveira (2002) para o Reservatório de Rosana e rio Tibagi, respectivamente. No presente, distribuiu-se nos reservatórios de Jurumirim, Chavantes, Salto Grande, Capivara e Rosana, ocorrendo em $71 \%$ das estações de amostragem (tabela 1).

Material examinado: BRASIL. SÃo PaUlo: rio Paranapanema, Reservatório de Jurumirim, sedimento, 24-XI-2006, L. Fontana s.n. (SP390881, SP390883); Divisa ParanÁ/São Paulo: rio Paranapanema, Reservatório de Chavantes, sedimento, 19-IV-2006, L. Fontana s.n. (SP390390884, SP390885, SP390886); Reservatório de Salto Grande, sedimento, 17-I-2006, L. Fontana s.n. (SP390887, SP390888); Reservatório de Capivara, sedimento, 17-I-2006, L. Fontana s.n. (SP390891, SP390892); Reservatório de Rosana, sedimento, 8-VI-2006, L. Fontana s.n. (SP390893).

\section{GOMPHONEMATACEAE}

\section{Gomphonema Ehrenberg}

\section{Chave para táxons de Gomphonema}

1. Valvas nitidamente claviformes

2. Extremidade apical amplamente arredondada ... G. laticollum

2. Extremidade apical com pólo mediano

pronunciado G. acuminatum

1. Valvas de outra forma
3. Extremidades estreitamente atenuadoarredondada G. gracile

3. Extremidades rostradas a capitadas

4. Extremidade apical nitidamente capitada ...... G. subtile

4. Extremidade apical rostrada a subcapitada

5. Extremidade basal reduzida, estrias retas ....... G. parvulum

5. Extremidade basal alongada, estrias curvado-radiadas G. lagenula

Gomphonema acuminatum Ehrenberg, Abh. der König. Akad. Wiss. Berl. p. 88. 1832.

Figura 20

Valvas clavadas, extremidade apical ampla, alargada no pólo mediano, extremidade basal afilada; estrias paralelas a curvado-radiadas, de difícil visualização. Medidas: 49-52 $\mu \mathrm{m}$ compr., 9,1-12,9 $\mu \mathrm{m}$ larg., estrias $13 \mathrm{em} 10 \mu \mathrm{m}$.

A espécie é facilmente caracterizada pelo formato clavado da valva. Difere de G. coronatum Ehrenberg pela extremidade apical mais inflada (Kociolek 2011). Já foi reportada para o Estado do Paraná (Procopiak et al. 2006, Tremarin et al. 2009, Bertolli et al. 2010), região Centro-Oeste brasileira (Silva et al. 2011) e para o Estado de São Paulo (Marquadt 2012). É a primeira citação de ocorrência da espécie para a área de estudo, onde ocorreu apenas no Reservatório de Jurumirim, em $21 \%$ das estações de amostragem (tabela 1).

Material examinado: BRASIL. São PAULO: rio Paranapanema, Reservatório de Jurumirim, sedimento, 24-XI-2006, L. Fontana s.n. (SP390881, SP390882, SP390883).

Gomphonema gracile Ehrenberg, in Die Infus. Vollk. Organ. Ein. Tief. organis. Leben de Natur. p. 217, pl. 18, fig. 3. 1838.

Figura 21-22

Valvas levemente heteropolares, lanceoladas, extremidade apical estreitamente atenuadoarredondada, extremidade basal atenuado-arredondada, estreita, área axial linear, estreita, área central limitada pelo encurtamento de uma estria, estigma presente na base da estria mediana alongada, rafe filiforme, extremidades proximais suavemente fletidas; estrias paralelas, tornando-se levemente radiadas em direção às extremidades. Medidas: 56,0-60,2 $\mu \mathrm{m}$ compr., 12,4-13,5 $\mu \mathrm{m}$ larg., estrias $15 \mathrm{em} 10 \mu \mathrm{m}$.

Estudos populacionais e com o material-tipo são necessários, pois se trata de uma espécie com grande 

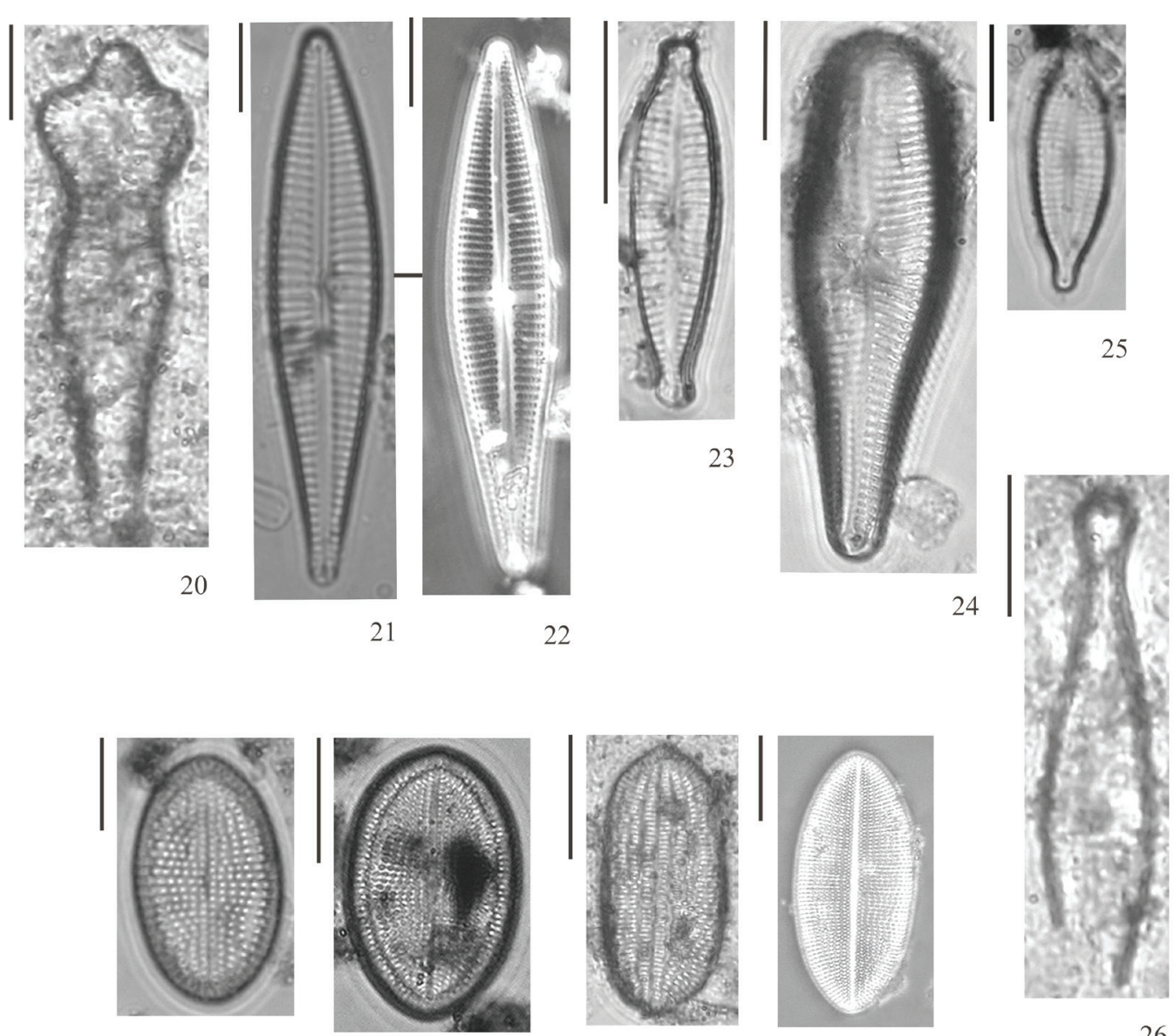

27

28

29

30
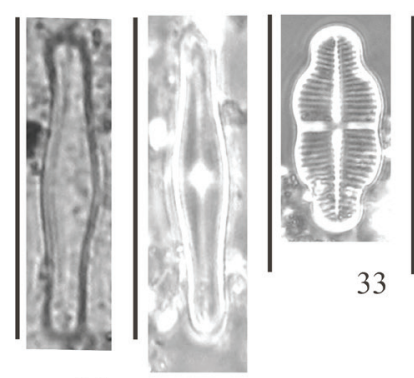

33

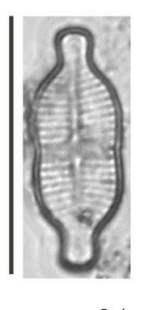

34

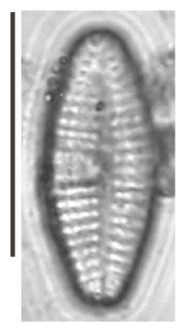

35

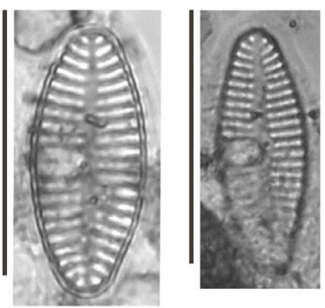

36

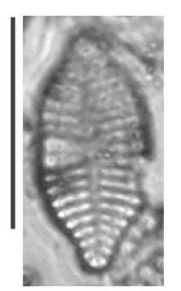

38

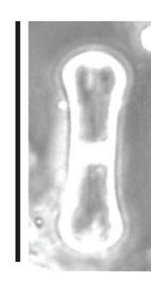

39

31

32

Figuras 20-39. Representantes da Classe Bacillariophyceae. 20. Gomphonema acuminatum Ehrenberg. 21-22. Gomphonema gracile Ehrenberg. 23. Gomphonema lagenula Kützing. 24. Gomphonema laticollum Reichart. 25. Gomphonema parvulum Kützing. 26. Gomphonema subtile Ehrenberg. 27-30. Cocconeis placentula Ehrenberg. 27, 28. Valvas com rafe. 28, 30. Valvas sem rafe. 31-32. Achnanthidium catenatum (Bily \& Marvan) Lange-Bertalot. 31. Valvas sem rafe. 32. Valvas com rafe. 33-34. Achnanthidium exiguum (Grunow) Czarnecki. 33, 34. Valvas com rafe. 35-37. Planothidium lanceolatum (Brébisson ex Kützing) Lange-Bertalot. 38. Planothidium rostratum (Östrup) Lange-Bertalot. 39. Diadesmis contenta (Grunow ex Van Heurck) Mann. 35, 36, 37, 38, 39. Valvas sem rafe. Barra da escala $=10 \mu \mathrm{m}$.

Figures 20-39. Taxa of Bacillariophyceae. 20. Gomphonema acuminatum Ehrenberg. 21-22. Gomphonema gracile Ehrenberg. 23. Gomphonema lagenula Kützing. 24. Gomphonema laticollum Reichart. 25. Gomphonema parvulum Kützing. 26. Gomphonema subtile Ehrenberg. 27-30. Cocconeis placentula Ehrenberg. 27, 28. Valves with raphe. 28, 30. Valves without raphe. 31-32. Achnanthidium catenatum (Bily \& Marvan) Lange-Bertalot. 31. Valves without raphe. 32. Valves with raphe. 33-34. Achnanthidium exiguum (Grunow) Czarnecki. 33, 34. Valves with raphe. 35-37. Planothidium lanceolatum (Brébisson ex Kützing) Lange-Bertalot. 38. Planothidium rostratum (Östrup) Lange-Bertalot. 39. Diadesmis contenta (Grunow ex Van Heurck) Mann. 35, 36, 37, 38, 39. Valves without raphe. Scale bar $=10 \mu \mathrm{m}$. 
variabilidade morfológica em relação ao contorno e às dimensões valvares (Tremarin et al. 2009).

De acordo com Eskinazi-Leça et al. (2012), trata-se de uma espécie amplamente distribuída no Brasil, ocorrendo principalmente nos Estados de Goiás e no Distrito Federal (região Centro-oeste), São Paulo e Rio de Janeiro (região Sudeste) e nos Estados do Paraná e Rio Grande do Sul (Região Sul). Particularmente para o Estado do Paraná, a espécie foi bem documentada (ex. Cetto et al. 2004, Ludwig et al. 2005, Procopiak et al. 2006). Para a área de estudo, distribuiu-se nos reservatórios de Capivara e Rosana, ocorrendo em $29 \%$ das estações de amostragem (tabela 1). O táxon já foi citado por Bittencourt-Oliveira (2002) para o rio Tibagi.

Material examinado: BRASIL. Divisa PARANÁ/São PAULO: rio Paranapanema, Reservatório de Capivara, sedimento, 17-I-2006, L. Fontana s.n. (SP390890, SP390891); Reservatório de Rosana, sedimento, 8-VI-2006, L. Fontana s.n. (SP390893, 390894).

Gomphonema lagenula Kützing, in Kützing. Bacill. Nordh. oder Diat. p. 85, pl. 30, fig. 60. 1844. Figura 23

Valvas heteropolares, lanceoladas, extremidades rostradas a subcapitadas, extremidade basal mais alongada do que a apical, área axial linear, área central limitada pelo encurtamento de estria, estrias curvado-radiadas, interestria maior do que estria na região mediana da valva, estigma presente na região central da valva, de difícil visualização, rafe filiformes. Medidas: 20,0-22,3 $\mu \mathrm{m}$ compr., 4,1-5,1 $\mu \mathrm{m}$ larg., estrias 9 em $10 \mu \mathrm{m}$.

Gomphonema lagenula Kützing e G. parvulum Kützing já foram consideradas sinônimos (VanLandingham 1967-1979) e o grupo lagenula como variedade de G. parvulum Kützing (Frengueli 1923). Todavia, no presente estudo, os indivíduos não apresentaram formas intermediárias entre as espécies mencionadas, concordando com a circunscrição e ilustrações de G. lagenula Kützing em Metzeltin et al. (2005) e Metzeltin \& Lange-Bertalot (2007)

Gomphonema lagenula Kützing foi anteriormente citada em águas paranaenses como G. parvulum var. lagenula (Kützing) Frenguelli (Moreira-Filho \& Mônoli 1963) e como pertencente aos morfotipos de G. parvulum Kützing (ex. Tavares \& Valente-Moreira 2000, Bittencourt-Oliveira 2002, Moura \& BittencourtOliveira 2004, Ludwig et al. 2005). Em estudo mais recente, Faria et al. (2010) apresentaram populações de $G$. parvulum e de G. lagenula separando-as, sobretudo, pela presença de ápice basal mais alongado na segunda.

Conforme Marquardt (2012), já foi citada para a área de estudo como G. parvulum por Bicudo et al. (1993). Foi encontrada apenas no Reservatório de Jurumirim, ocorrendo em 14\% das estações de amostragem (tabela 1).

Material examinado: BRASIL. São PAULO: rio Paranapanema, Reservatório de Jurumirim, sedimento, 24-XI-2006, L. Fontana s.n. (SP390881, SP390882).

Gomphonema laticollum Reichardt, in LangeBertalot. Studies on Diatoms. pl. 5, fig. 1-14. 2001 Figura 24

Valvas claviformes, extremidade apical amplamente arredondada, área axial linear, levemente ondulada, área central limitada pelo encurtamento de estrias, estigma presente na base de estria mediana alongada, rafe filiforme, extremidades proximais suavemente fletidas para o mesmo lado; estrias convergentes a radiadas. Medidas: 43,0-44,7 $\mu \mathrm{m}$ compr., 14,2-16 $\mu \mathrm{m}$ larg., estrias $11 \mathrm{em} 10 \mu \mathrm{m}$.

Gomphonema laticollum Reichardt assemelha-se à G. capitatum Ehrenberg e à G. truncatum Ehrenberg, das quais difere pela constrição menos pronunciada próxima à extremidade apical da valva (Reichardt 2001).

Há registros de G. laticollum Reichardt para o Estado do Paraná, porém, na maioria, como G. truncatum Ehrenberg, exceto ao registro de Lozovei \& Shirata (1990) que não pôde ser confirmado em razão da ausência de descrição, ilustração e ultraestrutura da valva (Tremarin et al. 2009). A espécie também foi reportada para esse Estado como G. truncatum var. capitatum (Ehrenberg) Patrick \& Reimer (Moro et al. 1994).

Os materiais examinados concordam plenamente com a população registrada para o rio Maurício, no Estado do Paraná (Tremarin et al. 2009). A espécie também foi citada para o Estado de São Paulo por Rodrigues (1991), tratando-se muito provavelmente de sua primeira citação para esse, sendo posteriormente reportada por Marquardt (2012). Para a área de estudo, foi identificada como Gomphonema truncatum Ehrenberg por Bicudo et al. (1993) para o Reservatório de Rosana. Distribuiu-se, no presente estudo, nos reservatórios de Jurumirim, Capivara e Rosana, ocorrendo em $29 \%$ das estações de amostragem (tabela 1). 
Material examinado: BRASIL. São Paulo: rio Paranapanema, Reservatório de Jurumirim, sedimento, 24-XI-2006, L. Fontana s.n. (SP390882); Divisa PARANÁ/SÃo PAULO: rio Paranapanema, Reservatório de Capivara, sedimento, 17-I-2006, L. Fontana s.n. (SP390890, SP390891); Reservatório de Rosana, sedimento, 8-VI-2006, L. Fontana s.n. (SP390893).

Gomphonema parvulum Kützing (Kützing), in Spec. Algar. p. 65. 1849.

Figura 25

Valvas heteropolares, lanceoladas, extremidade apical rostrada, extremidade basal afilada, área axial linear, área central limitada pelo encurtamento de uma estria, interestria maior do que a estria na região mediana da valva, estigma presente na região mediana, de difícil visualização, rafe filiforme, estrias retas, levemente radiadas em toda a valva. Medidas: 22,0-27,5 $\mu \mathrm{m}$ compr., 7,3-8,9 $\mu \mathrm{m}$ larg., estrias $7 \mathrm{em}$ $10 \mu \mathrm{m}$.

Gomphonema parvulum Kützing difere de G. lagenula Kützing pelo ápice basal menos alongado, rostrado a sub-rostrado, e pelas estrias retas e não radiado-curvadas (Krammer \& Lange-Bertalot 1991). Todavia, a grande variabilidade morfológica da espécie tem causado problemas na identificação taxonômica desde 1972 (Dawson 1972), dificultando a efetiva circunscrição de G. parvulum Kützing (Silva et al. 2001).

A espécie já foi registrada nas regiões Centro-Oeste, Sudeste e Sul do Brasil (Eskinazi-Leça et al. 2012), sendo amplamente citada no Estado do Paraná (ex. Tavares \& Valente-Moreira 2000, Moura \& Bittencourt-Oliveira 2004, Ludwig et al. 2005, Procopiak et al. 2006, Torgan et al. 2009, Tremarin et al. 2009, Bertolli et al. 2010, Faria et al. 2010). No Estado de São Paulo, foi documentada em poucos trabalhos (Bicudo et al. 2009, Bere \& Tundisi 2010), sendo dois para a área de estudo, Reservatório de Rosana (Bicudo et al. 1993) e rio Tibagi (BittencourtOliveira 2002). Mais recentemente, a distribuição da espécie no Estado de São Paulo foi bastante ampliada por Marquardt (2012). No presente trabalho, distribuiu-se nos reservatórios de Jurumirim, Chavantes, Salto Grande e Capivara, ocorrendo em 57\% das estações de amostragem (tabela 1).

Material examinado: BRASIL. SÃo Paulo: rio Paranapanema, Reservatório de Jurumirim, sedimento, 24-XI-2006, L. Fontana s.n. (SP390881, SP390882, SP390883); Divisa ParanÁ/São Paulo: rio Paranapanema, Reservatório de Chavantes, sedimento, 19-IV-2006, L. Fontana s.n. (SP390886); Reservatório de Salto Grande, sedimento, 17-I-2006, L. Fontana s.n. (SP390888, SP390889); Reservatório de Capivara, sedimento, 17-I-2006, L. Fontana s.n. (SP390891, SP390892).

Gomphonema subtile Ehrenberg, Abh. König. Akad. Wiss. Berl. 1: 416.1841 (1843).

Figura 26

Valvas heteropolares, extremidade apical capitada, estrias paralelas de difícil visualização. Medidas: ca. $40 \mu \mathrm{m}$ compr., 8,2 $\mu \mathrm{m}$ larg.

Foi encontrado apenas um indivíduo com a valva incompleta, razão pela qual a heteropolaridade não foi visualizada por completo, porém bem característico devido à forma valvar desta espécie. A mesma foi reportada em poucos trabalhos, tanto para o Estado do Paraná (ex. Silva et al. 2007) quanto para o Estado de São Paulo (ex. Graça et al. 2007, Bicudo et al. 2009, Marquardt 2012). É a primeira ocorrência do táxon para a área de estudo, onde se distribuiu apenas no Reservatório de Capivara, ocorrendo em 7\% das estações de amostragem (tabela 1).

Material examinado: BRASIL. Divisa PARANÁ/São PAUlo: rio Paranapanema, Reservatório de Capivara, sedimento, 17-I-2006, L. Fontana s.n. (SP390891).

\section{ACHNANTHALES \\ COCCONEIDACEAE \\ Cocconeis Ehrenberg}

Cocconeis placentula Ehrenberg, Die Infus. Vollk. Organis. Ein Tief. organis. Natur. p. 194, pl. 1-64, 1838

Figuras 27-30

Valvas ovado-elípticas a elípticas, extremidades arredondado-acuminadas; valva sem rafe: área axial linear, estreita, estrias unisseriadas, radiadas em direção às extremidades valvares, aréolas interrompidas por linhas hialinas longitudinais; valva com rafe: área axial estreita linear, estrias paralelas a radiadas em toda a extensão valvar, tornando-se curvado-radiadas em direção às extremidades, aréolas interrompidas por linhas hialinas longitudinais. Medidas: 21,0-31,4 $\mu \mathrm{m}$ compr., 10-16 $\mu \mathrm{m}$ larg., linhas longitudinais 10-17, aréolas 9-23 em $10 \mu \mathrm{m}$.

As variedades desta espécie distinguem-se pelo número de linhas longitudinais e forma das aréolas na valva arrafídea. Assim, a valva arrafídea da 
variedade típica caracteriza-se por apresentar 16-18 linhas longitudinais e aréolas delicadas de formato circular (Carneiro 2003). Os materiais analisados apresentaram grande variabilidade morfológica, tais como na forma dos ápices e aréolas, que variam de circular a circular-alongadas. Dessa forma, optou-se pela identificação em nível específico, devido, principalmente, à ausência de observações das características ultraestruturais (ex. forma das aréolas) importantes para a distinção entre as variedades da espécie.

A espécie já foi citada para as regiões Sudeste e Sul do Brasil (Eskinazi-Leça et al. 2012) e, particularmente, para o Estado de São Paulo destaca-se o trabalho florístico de Carneiro (2003). Trata-se da primeira ocorrência do táxon para a área de estudo, onde se distribuiu nos reservatórios de Jurumirim, Chavantes, Salto Grande e Capivara, ocorrendo em $64 \%$ das estações de amostragem (tabela 1).

Material examinado: BRASIL. São PAULo: rio Paranapanema, Reservatório de Jurumirim, sedimento, 24-XI-2006, L. Fontana s.n. (SP390881, SP390882, SP390883); Divisa Paraná/São Paulo: rio Paranapanema, Reservatório de Chavantes, sedimento, 19-IV-2006, L. Fontana s.n. (SP390886); Reservatório de Salto Grande, sedimento, 17-I-2006, L. Fontana s.n. (SP390888, SP390889); Reservatório de Capivara, sedimento, 17-I-2006, L. Fontana s.n. (SP390891, SP390892).

\section{ACHNANTHIDIACEAE}

\section{Achnanthidium Kützing}

Chave para táxons de Achnanthidium

1. Valvas com intumescimento mediano ... A. catenatum 1. Valvas sem intumescimento mediano ..... A. exiguum

Achnanthidium catenatum (Bily \& Marvan) LangeBertalot, in Icon. Diat. Annot. Diat. Microg. Phy. Sc. König. 6: 277. 1999.

Figuras 31-32

Valvas lineares, extremidades rostradas, levemente direcionadas para lados opostos, leve intumescência na região mediana da valva; valva com rafe: área axial linear, de difícil visualização, estrias inconspícuas; valva sem rafe: área axial linear, área central elíptica, estrias inconspícuas, de difícil visualização; valva em vista lateral com formato de "C", convexa, formando cadeias. Medidas: 9,6-9,8 $\mu \mathrm{m}$ compr., 1,4-1,7 $\mu \mathrm{m}$ larg., estrias inconspícuas não passíveis de visualização ao MO.

Achnanthidium catenatum (Bily \& Marvan) Lange-Bertalot é facilmente reconhecida em vista lateral (ou conectival) pela presença de valvas fortemente arqueadas em forma de "C" (Carneiro 2003). Em vista valvar aproxima-se de A. minutissimum Kützing, diferindo-se desta, mais facilmente, pela vista lateral. As principais características morfométricas utilizadas para distinguir A. catenatum (Bily \& Marvan) Lange-Bertalot dos demais táxons similares do gênero (ex. complexo A. minutissimum) são: forma valvar, padrão de estriação e dimensões valvares (Hlúbiková et al. 2011). Os materiais examinados concordam plenamente com o material-tipo reexaminado por Hlúbiková et al. (2011).

O táxon já foi reportando para o Estado de São Paulo em trabalho paleolimnológico (Costa-Böddeker et al. 2012) e taxonômico (Carneiro 2003). Trata-se da primeira ocorrência para a área de estudo, onde se distribuiu apenas no Reservatório de Rosana, ocorrendo em 14\% das estações de amostragem (tabela 1).

Material examinado: BRASIL. Divisa ParanÁ/São PAULO: rio Paranapanema, Reservatório de Rosana, sedimento, 8-VI-2006, L. Fontana s.n. (SP390893, 390894).

Achnanthidium exiguum (Grunow) Czarnecki, in Mem. Cal. Acad. Sc. 17: 157. 1994. Figuras 33-34

Valvas linear-lanceoladas, extremidades capitadas, constrição mediana valvar; valva com rafe: área axial linear, estreita, área central linear, expandida lateralmente, alcançando as margens, rafe filiforme, estrias radiadas em direção às extremidades da valva; valva sem rafe: área axial linear-lanceolada, estreita, área central lateralmente expandida, estrias radiadas em direção às extremidades da valva. Medidas: 8,1-10 $\mu \mathrm{m}$ compr., 3,1-3,4 $\mu \mathrm{m}$ larg., estrias de difícil quantificação.

O táxon já foi citado para o Estado do Paraná (Ferrari \& Ludwig 2007, Faria et al. 2010). Para a área de estudo, foi reportado como Achnanthes exigua var. exigua para o Reservatório de Rosana (Bicudo et al. 1993). Neste estudo, distribuiu-se nos reservatórios de Jurumirim, Salto Grande, Capivara e Rosana, ocorrendo em $29 \%$ das estações de amostragem (tabela 1). 
Material examinado: BRASIL. São Paulo: rio Paranapanema, Reservatório de Jurumirim, sedimento, 24-XI-2006, L. Fontana s.n. (SP390883); Divisa PARANÁ/SÃo PAULO: rio Paranapanema, Reservatório de Salto Grande, sedimento, 17-I-2006, L. Fontana s.n. (SP390887); Reservatório de Capivara, sedimento, 17-I-2006, L. Fontana s.n. (SP390891); Reservatório de Rosana, sedimento, 8-VI-2006, L. Fontana s.n. (390894).

Planothidium Round \& Bukhtiyarova

\section{Chave para táxons de Planothidium}

1. Extremidades arredondadas ................ P. lanceolatum 1. Extremidades rostradas P. rostratum

Planothidium lanceolatum (Brébisson ex Kützing) Lange-Bertalot, Icon. Diat. Ann. Diat., 6: 287.1999. Figuras 35-37

Valvas elíptico-lanceoladas, extremidades arredondadas; valva sem rafe: área axial linear a linear-lanceolada, presença de estrutura em forma de ferradura em um dos lados da valva; estrias radiadas a curvado-radiadas; valva com rafe não visualizada. Medidas: 9,6-11,4 $\mu \mathrm{m}$ compr., 3,6-5,0 $\mu \mathrm{m}$ larg., estrias 16-20 em $10 \mu \mathrm{m}$.

A espécie já foi reportada para os Estados do Paraná (Procopiak et al. 2006, Santos et al. 2011) e São Paulo (Eskinazi-Leça et al. 2012). Trata-se da primeira ocorrência para a área de estudo, onde se distribuiu nos reservatórios de Jurumirim, Salto Grande e Capivara, ocorrendo em 29\% das estações de amostragem (tabela 1).

Material examinado: BRASIL. SÃo PaUlo: rio Paranapanema, Reservatório de Jurumirim, sedimento, 24-XI-2006, L. Fontana s.n. (SP390883); Divisa PARANÁ/SÃo PAULO: rio Paranapanema, Reservatório de Salto Grande, sedimento, 17-I-2006, L. Fontana s.n. (SP390887, SP390888); Reservatório de Capivara, sedimento, 17-I-2006, L. Fontana s.n. (SP390891).

Planothidium rostratum (Östrup) Lange-Bertalot, in Icon. Diat. Ann. Diat. 6: 285. 1999.

Figura 38

Valvas lanceoladas, extremidades rostradas; valva sem rafe: área axial linear-lanceolada, área central irregular, presença de estrutura em forma de ferradura e um dos lados da valva, estrias radiadas em toda a extensão valvar; valva com rafe não visualizada. Medidas: 11,1 $\mu \mathrm{m}$ compr., 5,7 $\mu \mathrm{m}$ larg., estrias $18 \mathrm{em}$ $10 \mu \mathrm{m}$.

A espécie foi reportada para o Estado do Paraná (Ferrari \& Ludwig 2007) e para a Reserva Biológica de Paranapiacaba no Estado de São Paulo (Bicudo et al. 2009). Na área de estudo, foi registrada apenas no Reservatório de Jurumirim, ocorrendo em 14\% das estações de amostragem (tabela 1).

Material examinado: BRASIL. São PAUlo: rio Paranapanema, Reservatório de Jurumirim, sedimento, 24-XI-2006, L. Fontana s.n. (SP390881, SP390882).

\section{NAVICULALES \\ DIADESMIDACEAE \\ Diadesmis Kützing}

Diadesmis contenta (Grunow ex Van Heurck) Mann, in Round, Crawford \& Mann. The Diatoms. p. 666. 1990.

Figura 39

Valvas lineares, margens valvares côncavas, extremidades alargadas, arredondadas, área axial linear, estreita, área central retangular expandida até as margens, rafe filiforme, de difícil visualização, estrias inconspícuas de difícil visualização e contagem. Medidas: 7,8-8,7 $\mu \mathrm{m}$ compr., 1,9-2,1 $\mu \mathrm{m}$ larg.

Trata-se de espécie com ampla distribuição no Brasil, especialmente nas regiões Sul (Oliveira et al. 2001, Santos et al. 2011) e Sudeste do país (Eskinazi-Leça et al. 2012). No Estado de São Paulo foi reportada em estudo paleolimnológico de represa urbana (Costa-Böddeker et al. 2012). Para a área de estudo, trata-se da primeira ocorrência, onde se distribuiu apenas no Reservatório de Rosana, ocorrendo em $14 \%$ das estações de amostragem (tabela 1).

Material examinado: BRASIL. Divisa ParanÁ/São PAUlo: rio Paranapanema, Reservatório de Rosana, sedimento, 8-VI-2006, L. Fontana s.n. (SP390893, 390894).

\section{Luticola Mann}

Chave para táxons de Luticola

1. Valvas lanceoladas, extremidades cuneadas L. dapalis

1. Valvas rômbico-lanceoladas, extremidades arredondadas L. cf. goeppertiana 
Luticola dapalis (Frenguelli) Mann, in Round, Crawford \& Mann. The Diatoms. p. 670. 1990. Figura 40

Valvas lanceoladas, extremidades cuneadas, área axial linear, área central expandida, limitada pelo encurtamento de estrias medianas, estigma próximo à área central, conspícuo, rafe filiforme, extremidades proximais fletidas para o mesmo lado; estrias radiadas a curvado-radiadas em direção às extremidades. Medidas: 51,3 $\mu \mathrm{m}$ compr., 15,8 $\mu \mathrm{m}$ larg., estrias 16 em $10 \mu \mathrm{m}$.

Há poucos registros da espécie para os Estados de São Paulo e Paraná. Os únicos estudos encontrados são os de Bicudo et al. (1993) e Ferrari \& Ludwig (2007). O primeiro refere-se a um espécime similar identificado como Navicula goeppertiana (Bleisch) H.L. Smith var. dapalis (Frenguelli) Lange-Bertalot para o Reservatório de Rosana. Neste estudo, a espécie distribuiu-se nos reservatórios de Jurumirim, Chavantes, Salto Grande e Capivara, ocorrendo em 43\% das estações de amostragem (tabela 1).

Material examinado: BRASIL. São Paulo: rio Paranapanema, Reservatório de Jurumirim, sedimento, 24-XI-2006, L. Fontana s.n. (SP390881, SP390883); Divisa Paraná/São Paulo: rio Paranapanema, Reservatório de Chavantes, sedimento, 19-IV-2006, L. Fontana s.n. (SP390886); Reservatório de Salto Grande, sedimento, 17-I-2006, L. Fontana s.n. (SP390887, SP390888); Reservatório de Capivara, sedimento, 17-I-2006, L. Fontana s.n. (SP390891).

Luticola cf. goeppertiana (Bleisch in Rabenhorst) Mann, in Round, Crawford \& Mann. The Diatoms. p.670. 1990.

Figuras 41-42

Valvas rômbico-lanceoladas, extremidades arredondadas, área axial linear a linear-lanceolada, área central expandida, não alcançando as margens da valva, estigma localizado próximo à área central, de difícil visualização, rafe filiforme, estrias radiadas. Medidas: 9,1-27,7 $\mu \mathrm{m}$ compr., 3,1-7,9 $\mu \mathrm{m}$ larg., estrias 13-19 em $10 \mu \mathrm{m}$.

Luticola goeppertiana apresenta grande variabilidade morfológica de forma que as características diagnósticas não são claras, necessitando análises ultraestruturais, morfométricas e ecológicas para uma diferenciação mais precisa (Pavlov et al. 2009). Os materiais analisados apresentaram características dessa espécie tais como estrias radiadas, compostas por aréolas grosseiras e presença de estigma isolado, localizado na região central da valva. Todavia, as valvas de formato romboide e as extremidades arredondadas não concordam com os materiais-tipo reexaminados por Pavlov et al. (2009), os quais possuem valvas mais lanceoladas e extremidades mais acuminadas. Dessa forma, optou-se manter o táxon como conferatum até que estudos sejam feitos principalmente ao microscópio eletrônico de varredura que auxiliaria na identificação do material pelas características ultraestruturais, tais como forma do estigma e presença ou ausência de pontuações no manto da valva.

Há registros da espécie no Estado do Paraná (Bicudo et al. 1993, Ferrari \& Ludwig 2007, Laux \& Torgan 2011, Moresco et al. 2011). Para a área de estudo, a mesma foi identificada como Navicula goeppertiana var. dapalis para o Reservatório de Rosana (Bicudo et al. 1993). Neste estudo, distribuiu-se nos reservatórios de Jurumirim, Chavantes, Capivara e Rosana, ocorrendo em 50\% das estações de amostragem (tabela 1).

Material examinado: BRASIL. São PAULO: rio Paranapanema, Reservatório de Jurumirim, sedimento, 24-XI-2006, L. Fontana s.n. (SP390881, SP390883); Divisa Paraná/São Paulo: rio Paranapanema, Reservatório de Chavantes, sedimento, 19-IV-2006, L. Fontana s.n. (SP390884, SP390885, SP390886); Reservatório de Capivara, sedimento, 17-I-2006, L. Fontana s.n. (SP390892); Reservatório de Rosana, sedimento, 8-VI-2006, L. Fontana s.n. (SP390893).

\section{AMPHIPLEURACEAE}

\section{Amphipleura Kützing}

Amphipleura lindheimerii Grunow var. lindheimerii, Verh. Zool. - Bot. Ges. Wein. 12: 469, pl. 13, fig. 11a-b. 1862.

Figura 43

Valvas rombo-lanceoladas, extremidades atenuado-arredondadas, área axial linear, estreita, alargando-se nas regiões terminais da valva, área central ausente; extremidades distais da rafe incluídas em costelas silicificadas, estrias de difícil visualização e contagem. Medidas: $90 \mu \mathrm{m}$ compr., 11,4-12 $\mu \mathrm{m}$ larg.

O táxon tem sido amplamente reportado nas regiões Sul (Santos et al. 2011, Soares et al. 2011) e Sudeste do Brasil (Eskinazi-Leça et al. 2012). Na área de estudo, já foi citado para o rio Tibagi (BittencourtOliveira 2002). No presente trabalho, distribuiu-se nos reservatórios de Salto Grande, Capivara e Rosana, ocorrendo em $29 \%$ das estações de amostragem (tabela 1). 

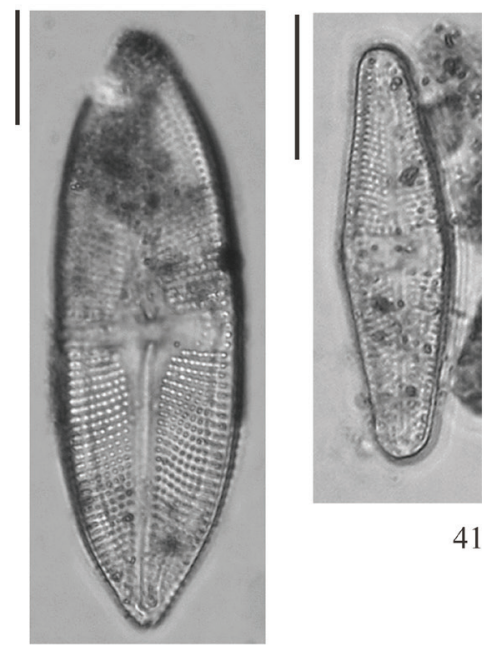

41

40

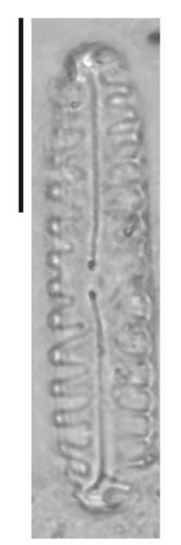

46

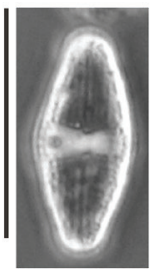

42

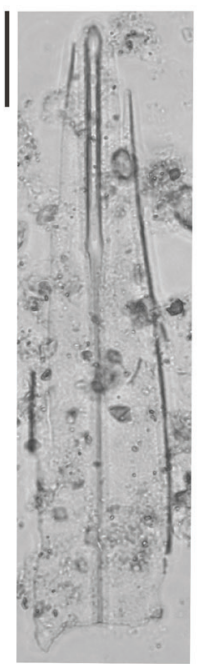

43

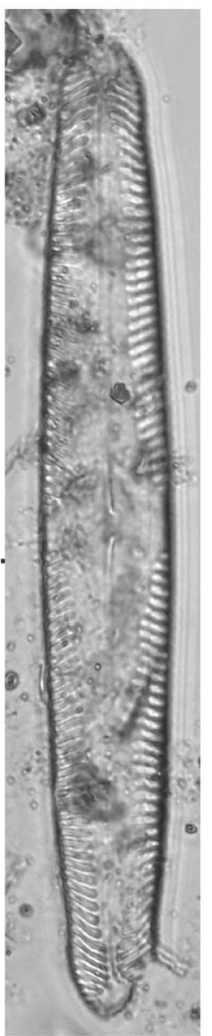

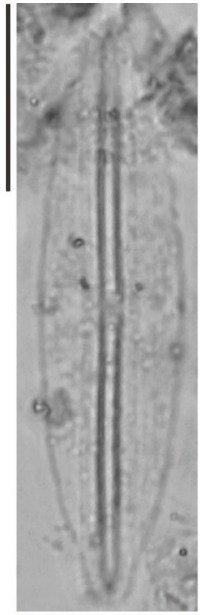

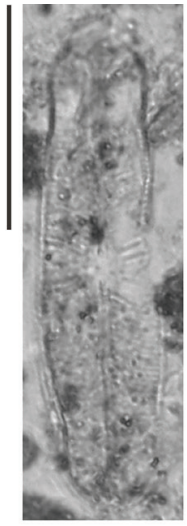

45
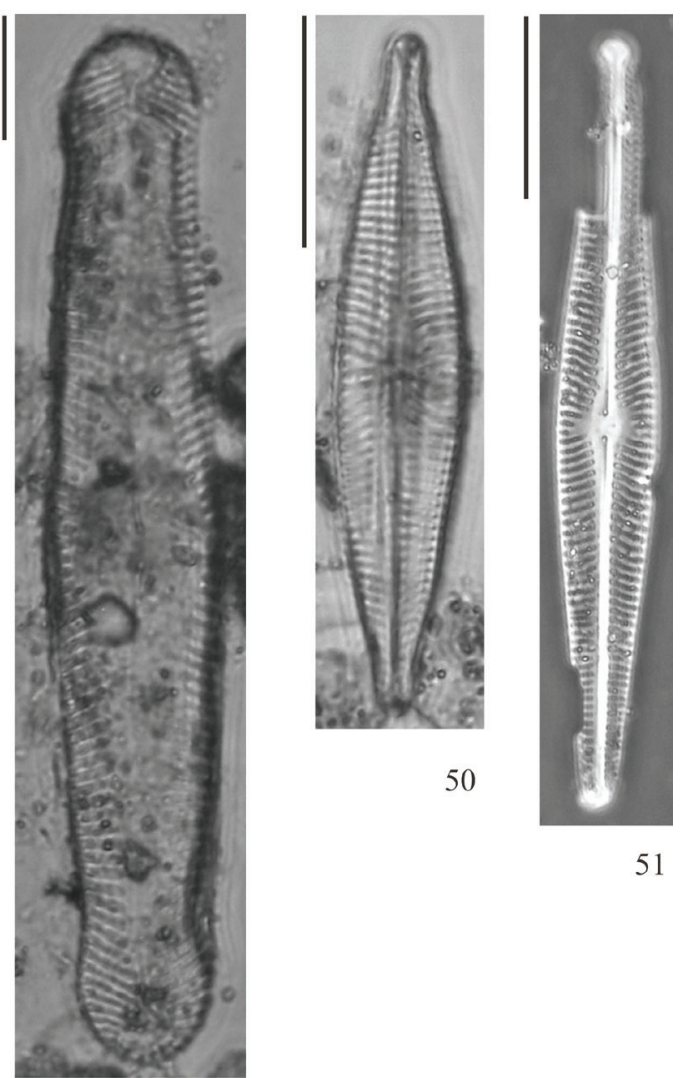

51

48

49

Figuras 40-51. Representantes da Classe Bacillariophyceae. 40. Luticola dapalis (Frenguelli) Mann. 41-42. Luticola cf. goeppertiana (Bleisch in Rabenhorst) Mann. 43. Amphipleura lindheimerii Grunow var. lindheimerii. 44. Frustulia saxonica Rabenhorst var. saxonica. 45. Sellaphora pupula (Kützing) Mereschkowsky. 46. Pinnularia borealis Ehrenberg. 47. Pinnularia dubitabilis Hustedt var. dubitabilis. 48. Pinnularia subgiba Krammer. 49. Pinnularia trigibboides Metzeltin \& Lange-Bertalot. 50. Navicula viridula (Kützing) Ehrenberg. 51. Navicula sp. Barra da escala $=10 \mu \mathrm{m}$.

Figures 40-51. Taxa of Bacillariophyceae. 40. Luticola dapalis (Frenguelli) Mann. 41-42. Luticola cf. goeppertiana (Bleisch in Rabenhorst) Mann. 43. Amphipleura lindheimerii Grunow var. lindheimerii. 44. Frustulia saxonica Rabenhorst var. saxonica. 45. Sellaphora pupula (Kützing) Mereschkowsky. 46. Pinnularia borealis Ehrenberg. 47. Pinnularia dubitabilis Hustedt var. dubitabilis. 48. Pinnularia subgiba Krammer. 49. Pinnularia trigibboides Metzeltin \& Lange-Bertalot. 50. Navicula viridula (Kützing) Ehrenberg. 51. Navicula sp. Scale bar $=10 \mu \mathrm{m}$. 
Material examinado: BRASIL. Divisa São PaUlo/ Paraná: rio Paranapanema, Reservatório de Salto Grande, sedimento, 17-I-2006, L. Fontana s.n. (SP390887, SP390888); Reservatório de Capivara, sedimento, 17-I-2006, L. Fontana s.n. (SP390891); Reservatório de Rosana, sedimento, 8-VI-2006, L. Fontana s.n. (SP390894).

\section{Frustulia Rabenhorst}

Frustulia saxonica Rabenhorst var. saxonica, Süss. Diatom. Freund. Mikrosk. p. 50, pl. 7, fig. 1. 1853. Figura 44

Valvas linear-lanceoladas, extremidades rostradas, área axial linear, estreita, rafe filiforme, situada entre costelas, levemente arqueada; estrias transversais paralelas e longitudinais suavemente onduladas, de difícil visualização e contagem; margem valvar lisa, arredondada. Medidas: 62,7 $\mu \mathrm{m}$ compr., 11,5 $\mu \mathrm{m}$ larg. Lange-Bertalot \& Jahn (2000), ao avaliarem o material-tipo de $F$. saxonica Rabenhorst, observaram variações morfométricas, que foram reconhecidas como dois morfotipos (I e II). Na literatura, o morfotipo I tem sido identificado como F. rhomboides (Ehrenberg) De Toni var. rhomboides e o morfotipo II, como F. rhomboides (Ehrenberg) De Toni var. saxonica (Laux \& Torgan 2011, Soares et al. 2011). Existe, ainda, certa confusão sobre os atributos morfológicos que diferenciam $F$. saxonica de $F$. crassinervia (Brébisson) Lange-Bertalot \& Krammer. A principal característica distintiva de $F$. saxonica Rabenhorst reside no contorno valvar destituído de ondulações (Brassac \& Ludwig 2005), cuja característica também a separa de F. rhomboides (Soares et al. 2011).

O material analisado concorda plenamente com a população observada por Brassac \& Ludwig (2005) na bacia do rio Iguaçu, Paraná. A espécie apresenta ampla distribuição geográfica no Brasil (Eskinazi-Leça et al. 2012) e, principalmente, no Estado do Paraná (Brassac \& Ludwig 2005, Laux \& Torgan 2011, Santos et al. 2011, Soares et al. 2011). Para o Estado de São Paulo não foi encontrado trabalho cujo material seja passível de reidentificação. Assim sendo, trata-se também da primeira ocorrência do táxon para a área de estudo, onde se distribuiu nos reservatórios de Jurumirim, Salto Grande, Capivara e Rosana, ocorrendo em 36\% das estações de amostragem.

Material examinado: BRASIL. São PAULO: rio Paranapanema, Reservatório de Jurumirim, sedimento, 24-XI-2006, L. Fontana s.n. (SP390882); Divisa Paraná/São Paulo: rio Paranapanema, Reservatório de Salto Grande, sedimento, 17-I-2006, L. Fontana s.n. (SP390889); Reservatório de Capivara, sedimento, 17-I-2006, L. Fontana s.n. (SP390890, SP390891); Reservatório de Rosana, sedimento, 8-VI-2006, L. Fontana s.n. (SP390893).

\section{SELLAPHORACEAE}

\section{Sellaphora Mereschkowsky}

Sellaphora pupula (Kützing) Mereschkowsky, Ann. Mag. Natur. Hist. ser. 7, 9: 187, pl. 4, fig. 1-5. 1902.

Figura 45

Valvas linear-lanceoladas, extremidades subcapitadas, área axial linear, rafe filiforme, estrias delicadamente radiadas, de difícil visualização, interestria maior do que estria na região mediana da valva. Medidas: 18,9-21,5 $\mu \mathrm{m}$ compr., 5,0-5,7 $\mu \mathrm{m}$ larg.

A identificação do material do rio Paranapanema levou em consideração a grande variabilidade morfológica registrada para o complexo $S$. pupula, conforme registrado em literatura (Behnke et al. 2004). Baseou-se, também, na revisão do gênero Sellaphora (Mann et al. 2008), na qual os materiais examinados se enquadraram. A espécie foi reportada em todas as regiões do país (Eskinazi-Leça et al. 2012). Particularmente para a área de estudo, foi identificada como Navicula pupula Kützing var. pupula para o Reservatório de Rosana (Bicudo et al. 1993). Neste estudo, distribuiu-se nos reservatórios de Jurumirim, Chavantes, Salto Grande, Capivara e Rosana, ocorrendo em $36 \%$ das estações de amostragem (tabela 1).

Material examinado: BRASIL. São PAULo: rio Paranapanema, Reservatório de Jurumirim, sedimento, 24-XI-2006, L. Fontana s.n. (SP390882); Divisa PARANÁ/São PAUlo: rio Paranapanema, Reservatório de Chavantes, sedimento, 19-IV-2006, L. Fontana s.n. (SP390886); Reservatório de Salto Grande, sedimento, 17-I-2006, L. Fontana s.n. (SP390889); Reservatório de Capivara, sedimento, 17-I-2006, L. Fontana s.n. (SP390891); Reservatório de Rosana, sedimento, 8-VI-2006, L. Fontana s.n. (SP390894).

\section{PINNULARIACEAE}

Pinnularia Ehrenberg

Chave para táxons de Pinnularia

1. Estrias robustas

2. Extremidades truncado-arredondadas P. dubitabilis var. dubitabilis

2. Extremidades arredondadas P. borealis 
1. Estrias não robustas

3. Extremidades subcapitadas P. subgiba

3. Extremidades capitadas P. trigibboides

Pinnularia borealis Ehrenberg, in Abh. der König. Akad. Wiss. Berl. p. 420 (132), pl. 1/2, fig. 6, pl. 4/1, fig. 5. 1843.

Figura 46

Valvas lineares, margens retas a onduladas, extremidades arredondadas, mais estreitas do que o restante da valva, área axial linear, área central irregular, rafe filiforme com extremidades proximais fletidas para o mesmo lado; estrias robustas, paralelas a radiadas. Medidas: 18,5-24,4 $\mu \mathrm{m}$ compr., 3,4-5,2 $\mu \mathrm{m}$ larg., estrias $9 \mathrm{em} 10 \mu \mathrm{m}$.

A espécie apresenta ampla distribuição geográfica no Brasil (Eskinazi-Leça et al. 2012). Para a área de estudo, já foi citada para o rio Tibagi (BittencourtOliveira 2002), ocorrendo ainda nos reservatórios de Jurumirim e Rosana, em $21 \%$ das estações de amostragem (tabela 1).

Material examinado: BRASIL. São PAUlo: rio Paranapanema, Reservatório de Jurumirim, sedimento, 24-XI-2006, L. Fontana s.n. (SP390882); Divisa PARANÁ/São PaUlo: rio Paranapanema, Reservatório de Rosana, sedimento, 8-VI-2006, L. Fontana s.n. (SP390893, SP390894).

Pinnularia dubitabilis Hustedt var. dubitabilis, Expl. Park. Nat. Albert. 8: 105. 1949.

Figura 47

Valvas lineares, retangulares, margens retas a suavemente onduladas, extremidades truncadoarredondadas, amplas, área axial linear, área central circular, assimétrica, limitada por estrias mais curtas, rafe filiforme com extremidades proximais fletidas para o mesmo lado; estrias robustas, longas, paralelas a levemente radiadas. Medidas: 24,5-29,7 $\mu \mathrm{m}$ compr., 4,1-5,6 $\mu \mathrm{m}$ larg., estrias 8-9 em $10 \mu \mathrm{m}$.

As características mais evidentes desta espécie consistem no contorno valvar retangular, com extremidades retas, estrias robustas e encurtadas (Hustedt 1949). Pinnularia dubitabilis difere de P. borealis Ehrenberg, sobretudo, pelas extremidades truncado-arredondadas e valvas mais retangulares na primeira e extremidades mais arredondadas e afiladas na segunda. Pinnularia dubitabilis já foi registrada para o Estado do Paraná (ex. Bittencourt-Oliveira 2002, Brassac \& Ludwig 2006), havendo um único registro para o Estado de São Paulo (Rocha 2008). Trata-se da primeira ocorrência para a área de estudo, onde se distribuiu nos reservatórios de Jurumirim,
Salto Grande, Capivara e Rosana, ocorrendo em 50\% das estações de amostragem (tabela 1).

Material examinado: BRASIL. São PaUlo: rio Paranapanema, Reservatório de Jurumirim, sedimento, 24-XI-2006, L. Fontana s.n. (SP390881, SP390882, SP390883); Divisa ParanÁ/São Paulo: rio Paranapanema, Reservatório de Salto Grande, sedimento, 17-I-2006, L. Fontana s.n. (SP390888, SP390889); Reservatório de Capivara, sedimento, 17-I-2006, L. Fontana s.n. (SP390892); Reservatório de Rosana, sedimento, 8-VI-2006, L. Fontana s.n. (SP390894).

Pinnularia subgiba Krammer, Bibl. Diat. 26: 126, 176, pl. 46, fig. 1-4, 6-7, pl. 47, fig. 2-4, 6. 1992. Figura 48

Valvas lineares, extremidades subcapitadas, área axial lanceolada, delimitada pelo encurtamento ou ausência de estrias na região mediana da valva, rafe filiforme com extremidades proximais fletidas para o mesmo lado; estrias de tamanhos desiguais ao longo da valva, convergentes no centro a radiadas nas margens. Medidas: 65,4-69,8 $\mu \mathrm{m}$ compr., 8,2-8,8 $\mu \mathrm{m}$ larg., estrias $14 \mathrm{em} 10 \mu \mathrm{m}$.

A espécie tem ampla distribuição na região Sudeste do país (Eskinazi-Leça et al. 2012), especialmente no Estado de São Paulo (Rocha \& Bicudo 2008). Os materiais examinados assemelham-se ao material encontrado no Parque Estadual das Fontes do Ipiranga (Rocha \& Bicudo 2008), principalmente em relação aos valores métricos da valva. É a primeira ocorrência para a área de estudo, onde foi encontrada apenas à montante do Reservatório de Jurumirim, ocorrendo em 7\% das estações de amostragem (tabela 1).

Material examinado: BRASIL. São PAUlo: rio Paranapanema, Reservatório de Jurumirim, sedimento, 24-XI-2006, L. Fontana s.n. (SP390881).

Pinnularia trigibboides Metzeltin \& Lange-Bertalot, Icon. Diatom. 18: 229, pl. 258, fig. 4-5. 2007. Figura 49

Valvas linear-lanceoladas, extremidades capitadas, área axial lanceolada, área central lateralmente expandida não alcançando as margens, rafe levemente ondulada, extremidades proximais fletidas para o mesmo lado; estrias radiadas a convergentes em direção à região mediana. Medidas: 82,4-89,1 $\mu \mathrm{m}$ compr., 10,1-14,48 $\mu \mathrm{m}$ larg., estrias 9 em $10 \mu \mathrm{m}$.

Os espécimes do presente trabalho concordam com a circunscrição da espécie na obra original (Metzeltin \& Lange-Bertalot 2007). Não foi encontrado registro 
da mesma para os Estados do Paraná e São Paulo (Eskinazi-Leça et al. 2012). Trata-se da primeira citação para bacia do rio Paranapanema, onde se distribuiu nos reservatórios de Jurumirim, Chavantes, Salto Grande, Capivara e Rosana, ocorrendo em 64\% das estações de amostragem (tabela 1).

Material examinado: BRASIL. São PAULo: rio Paranapanema, Reservatório de Jurumirim, sedimento, 24-XI-2006, L. Fontana s.n. (SP390881, SP390883); Divisa Paraná/São Paulo: rio Paranapanema, Reservatório de Chavantes, sedimento, 19-IV-2006, L. Fontana s.n. (SP390885, SP390886); Reservatório de Capivara, sedimento, 17-I-2006, L. Fontana s.n. (SP390891, SP390892); Reservatório de Rosana, sedimento, 8-VI-2006, L. Fontana s.n. (SP390894).

\section{NAVICULACEAE}

\section{Navicula Bory}

Chave para táxons de Navicula

1. Extremidades atenuadas, sub-rostradas .... N. viridula 1. Extremidades atenuado-arredondadas ... Navicula $\mathrm{sp}$.

Navicula viridula (Kützing) Ehrenberg, Infus. Vollk. Organis. I-II: 1-547, pl. 54. 1838.

Figura 50

Valvas lanceoladas, alargadas na região central, extremidades atenuadas, sub-rostradas, área axial linear, rafe filiforme, extremidades da rafe de difícil visualização; estrias encurvadas, radiadas a convergentes. Medidas: 24,2-29,3 $\mu \mathrm{m}$ compr., 5,3-5,7 $\mu \mathrm{m}$ larg., estrias $18 \mathrm{em} 10 \mu \mathrm{m}$.

A espécie difere de Navicula rostellata Kützing, principalmente, pela menor largura valvar. Apresenta-se amplamente distribuída no Brasil (Eskinazi-Leça et al. 2012), mas poucos trabalhos possuem material passível de reidentificação (ex. Oliveira et al. 2001, Bertolli et al. 2010). É a primeira ocorrência para a área de estudo, onde se distribuiu nos reservatórios de Jurumirim, Salto Grande e Capivara, ocorrendo em $29 \%$ das estações de amostragem (tabela 1).

Material examinado: BRASIL. São PAUlo: rio Paranapanema, Reservatório de Jurumirim, sedimento, 24-XI-2006, L. Fontana s.n. (SP390882); Divisa Paraná/São PaUlo: rio Paranapanema, Reservatório de Salto Grande, sedimento, 17-I-2006, L. Fontana s.n. (SP390887); Reservatório de Capivara, sedimento, 17-I-2006, L. Fontana s.n. (SP390890, SP390891).
Navicula sp.

Figura 51

Valvas linear-lanceoladas, pouco expandidas na região central, extremidades atenuado-arredondadas, área axial linear, margem limitada pelo encurtamento irregular das estrias, rafe filiforme, reta, extremidades proximais levemente fletidas para o mesmo lado; estrias curvado-radiadas, radiadas a suavemente convergentes em direção às extremidades. Medidas: 40,0-42,2 $\mu \mathrm{m}$ compr., 4,9-5,1 $\mu \mathrm{m}$ larg., estrias $20 \mathrm{em}$ $10 \mu \mathrm{m}$.

Os materiais examinados assemelham-se a duas espécies. Aproxima-se de Navicula notha Wallace, principalmente, pela presença de estrias curvado-radiadas, encurtadas no centro da valva, forma valvar lanceolada, área central reduzida e extremidade terminal da rafe fletidas para o mesmo lado (Potapova 2011). Contudo, N. notha Wallace apresenta comprimento valvar menor (18,7-39,3 $\mu \mathrm{m})$, menor densidade de estrias (14-17 $\mu \mathrm{m})$. Também se assemelha a $N$. cryptocephala Kützing pela forma valvar lanceolada, extremidades valvares atenuado-arredondadas e padrão de estriação curvadoradiadas (Potapova 2011). Difere, sobretudo, pela área central mais expandida e menor comprimento valvar (21-34 $\mu \mathrm{m})$ em $N$. cryptocephala. Como os exemplares examinados diferem dessas espécies mais próximas pelos valores métricos, conforme Potapova (2011), bem como pela forma valvar do material-tipo de $N$. cryptocephala Kützing (Kützing 1844), optamos pela não identificação em nível específico até que mais informações estejam disponíveis.

O táxon distribuiu-se nos reservatórios de Jurumirim e Rosana, ocorrendo em $21 \%$ das estações de amostragem (tabela 1).

Material examinado: BRASIL. São PAULo: rio Paranapanema, Reservatório de Jurumirim, sedimento, 24-XI-2006, L. Fontana s.n. (SP390882, SP390883); Divisa Paraná/São Paulo: rio Paranapanema, Reservatório de Rosana, sedimento, 8-VI-2006, L. Fontana s.n. (SP390893).

Geissleria Lange-Bertalot \& Metzeltin

Geissleria aikenensis (Patrick) Torgan \& Oliveira, Proc. $16^{\text {th }}$ Inter. Diatom. Sym. p 115-125, fig. 2-19. 2000.

Figura 52

Valvas lanceoladas, extremidades rostradas, área axial linear, área central arredondada, reduzida, rafe filiforme, reta; estrias radiadas em toda a superfície valvar, estrias medianas mais espaçadas. Medidas: 
19,2-21,1 $\mu \mathrm{m}$ compr., 5,0-5,9 $\mu \mathrm{m}$ larg., estrias $16 \mathrm{em} 10 \mu \mathrm{m}$.

Geissleria aikenensis (Patrick) Torgan \& Oliveira é caracterizada pelas valvas lanceoladas, extremidades apicais rostradas, presença de estigma central e estrias medianas espaçadas (Moresco et al. 2011). Foi registrada para o Estado do Paraná (ex. Moresco et al. 2011). Para o Estado de São Paulo, não foi encontrado registro de sua ocorrência. É citada pela primeira vez para a área de estudo, onde ocorreu apenas na região à montante do Reservatório de Jurumirim, distribuindo-se em $7 \%$ das estações de amostragem (tabela 1).

Material examinado: BRASIL. SÃo PaUlo: rio Paranapanema, Reservatório de Jurumirim, sedimento, 24-XI-2006, L. Fontana s.n. (SP390881).

\section{Capartogramma Kufferath}

Capartogramma crucicula (Grunow ex Cleve) Ross, Bul. of Brit. Mus. Ser. Bot. 3: 2, pl. 1, fig. B, pl. 2, fig. A, fig. T. la, 8-11. 1963.

Figura 53

Valvas linear-lanceoladas, extremidades rostradas, arredondadas, área axial linear, estreita, área central apresentando estauro tigilado. Medidas: $18 \mu \mathrm{m}$ compr., 5,5 $\mu \mathrm{m}$ larg.

Capartogramma crucicula já foi reportada para o Estado do Paraná (ex. Rodrigues 1991, Eskinazi-Leça et al. 2012). Para a área de estudo, foi registrada no Reservatório de Rosana (Bicudo et al. 1993), sendo reencontrada na região à montante do reservatório. Distribuiu-se em $7 \%$ das estações de amostragem (tabela 1).

Material examinado: BRASIL. Divisa PARANÁ/São PAULO: rio Paranapanema, Reservatório de Rosana, sedimento, 8-VI-2006, L. Fontana s.n. (SP390893).

\section{PLEUROSIGMATACEAE}

\section{Gyrosigma Hassal}

Gyrosigma nodiferum (Grunow) Reimer, Diat. Unit. St. 1: 320, pl. 24, fig. 2, 1966.

Figura 54

Valvas sigmoides, linear-lanceoladas, extremidades atenuado-arredondadas, área axial sigmóide, estreita, área central elíptica, rafe sigmoide; estrias transversais e longitudinais conspícuas. Medidas:
60,2-71,2 $\mu \mathrm{m}$ compr., 5,0-6,4 $\mu \mathrm{m}$ larg., estrias $41-43$ em $10 \mu \mathrm{m}$.

A espécie foi documentada para o Estado do Paraná por vários autores (ex. Brassac et al. 1999, Tremarin et al. 2009) e, ao que tudo indica, o presente estudo é a primeira citação passível de identificação para o Estado de São Paulo. Assim sendo, é também citada pioneiramente para a bacia do rio Paranapanema, sendo registrada apenas no Reservatório de Jurumirim e ocorrendo em 21\% das estações de amostragem (tabela 1).

Material examinado: BRASIL. São PAULo: rio Paranapanema, Reservatório de Jurumirim, sedimento, 24-XI-2006, L. Fontana s.n. (SP390881, SP390882, SP390883).

\section{CATENULACEAE}

\section{Amphora Ehrenberg}

Amphora copulata (Kützing) Schoeman \& Archibald, J. Afr. Bot. 52: 5, fig. 11-13, fig. 30-34. 1986.

\section{Figura 55}

Valvas dorsiventrais, margem dorsal convexa, margem ventral côncava, extremidades cuneadas, área axial estreita, área central expandida atingindo as margens valvares, rafe arqueda, extremidades proximais fletidas dorsalmente; estrias dorsais paralelas interrompidas na região mediana por uma área central regular, estrias ventrais radiadas. Medidas: 19,8-21,7 $\mu \mathrm{m}$ compr., 4,0-5,7 $\mu \mathrm{m}$ larg., estrias $13 \mathrm{em}$ $10 \mu \mathrm{m}$.

A espécie já foi reportada para o Estado do Paraná (Tremarin et al. 2009). Trata-se de sua primeira ocorrência para a área de estudo, onde foi registrada apenas no Reservatório de Capivara, em 14\% das estações de amostragem (tabela 1).

Material examinado: BRASIL. Divisa PARANÁ/São PAULO: rio Paranapanema, Reservatório de Capivara, sedimento, 17-I-2006, L. Fontana s.n. (SP390890, SP390891).

\section{BACILLARIALES \\ BACILLARIACEAE Nitzschia Hassal}

Chave para táxons de Nitzschia

1. Estrias robustas................................... N. amphibia

1. Estrias inconspícuas.................................... palea 

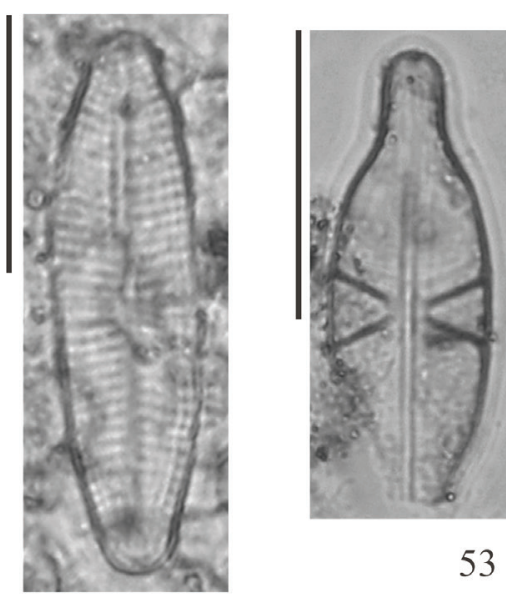

53

52
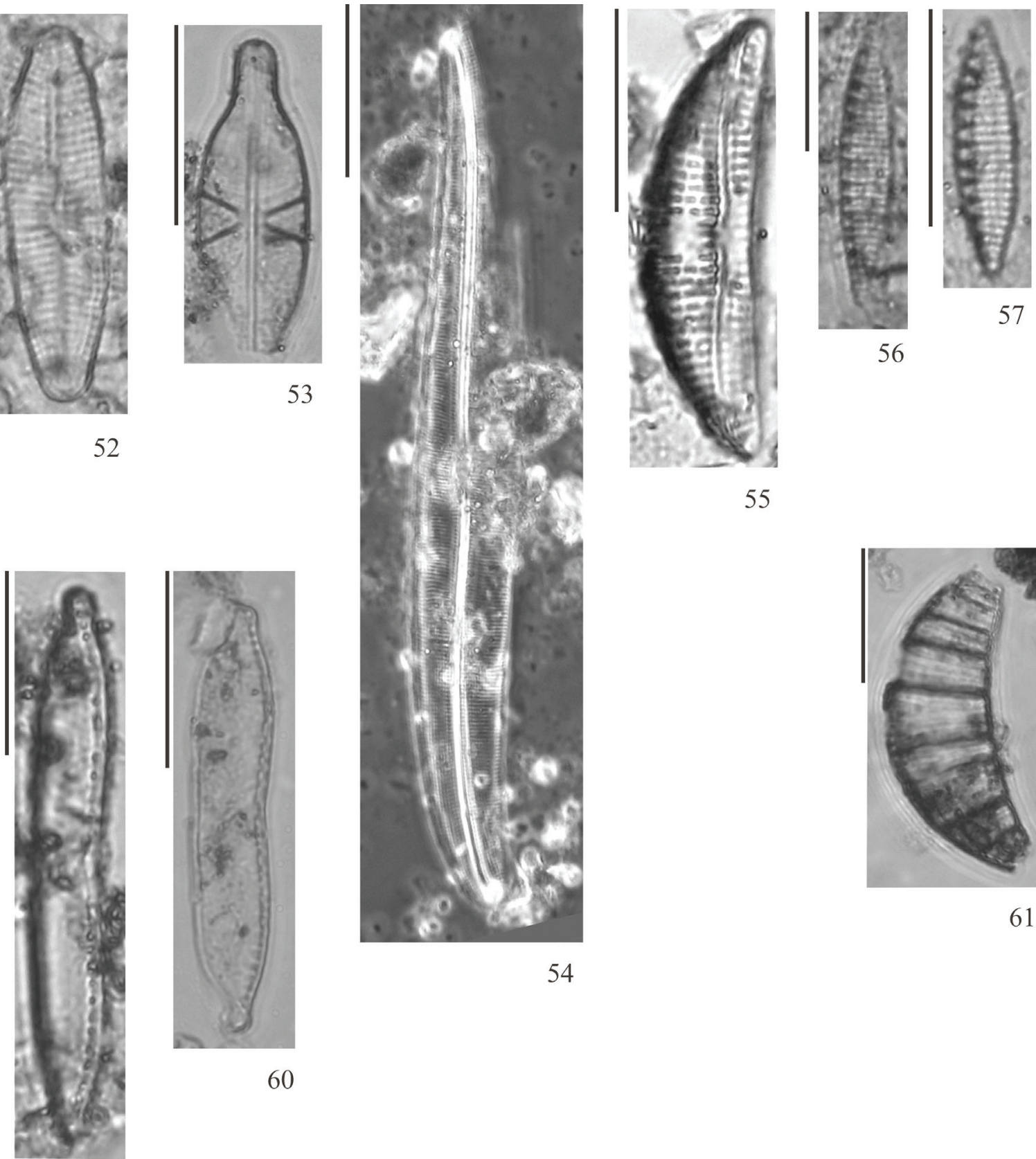

57

56

\section{5}

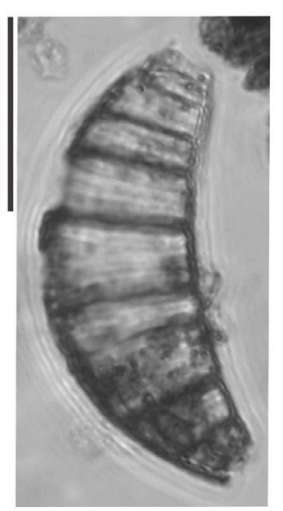

61

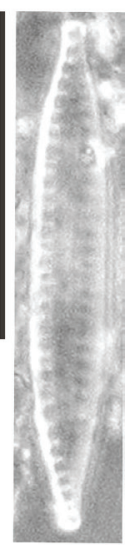

58

Figuras 52-61. Representantes da Classe Bacillariophyceae. 52. Geissleria aikenensis (Patrick) Torgan \& Oliveira. 53. Capartogramma crucicula (Grunow ex Cleve) Ross. 54. Gyrosigma nodiferum (Grunow) Reimer. 55. Amphora copulata (Kützing) Schoeman \& Archibald. 56-57. Nitzschia amphibia Grunow. 58. Nitzschia palea (Kützing) W. Smith. 59-60. Hantzschia amphioxys (Ehrenberg) Grunow. 61. Rhopalodia $\mathrm{sp}$. Barra da escala $=10 \mu \mathrm{m}$.

Figures 52-61. Taxa of Bacillariophyceae. 52. Geissleria aikenensis (Patrick) Torgan \& Oliveira. 53. Capartogramma crucicula (Grunow ex Cleve) Ross. 54. Gyrosigma nodiferum (Grunow) Reimer. 55. Amphora copulata (Kützing) Schoeman \& Archibald. 56-57. Nitzschia amphibia Grunow. 58. Nitzschia palea (Kützing) W. Smith. 59-60. Hantzschia amphioxys (Ehrenberg) Grunow. 61. Rhopalodia sp. Scale bar $=10 \mu \mathrm{m}$. 
Nitzschia amphibia Grunow, Verh. König. Zool. Botan. Ges. Wien. 12: 574, pl. 12, fig. 23. 1862.

Figuras 56-57

Valvas lanceoladas, extremidades atenuadoarredondadas; fíbulas marginais robustas, estrias conspícuas, estrias medianas paralelas a levemente radiadas próximas às extremidades. Medidas: 11,7-21,5 $\mu \mathrm{m}$ compr., 3,0-3,9 $\mu \mathrm{m}$ larg., estrias 23-26 em $10 \mu \mathrm{m}$, fíbulas 10-11 em $10 \mu \mathrm{m}$.

A espécie caracteriza-se pela presença de estrias caracteristicamente proeminentes (grosseiras) e distintamente pontuadas (Kociolek 2011). Vem sendo amplamente reportada para o Estado do Paraná desde a década de 1970 (ex. Lozovei \& Luz 1976, Brassac et al. 1999, Ludwig et al. 2005, Tremarin et al. 2009). Para o Estado de São Paulo também há registros de sua ocorrência (Eskinazi-Leça et al. 2012). O táxon já foi citado para a área de estudo no Reservatório de Rosana (Bicudo et al. 1993). No presente distribuiu-se apenas no Reservatório de Jurumirim, ocorrendo em $21 \%$ das estações de amostragem (tabela 1 ).

Material examinado: BRASIL. SÃo PaUlo: rio Paranapanema, Reservatório de Jurumirim, sedimento, 24-XI-2006, L. Fontana s.n. (SP390881, SP390882, SP390883).

Nitzschia palea (Kützing) W. Smith, Syn. Brit. Diat., 12: 89. 1856.

Figura 58

Valvas linear-lanceoladas, extremidades afiladas, estreitas, subcapitadas; fíbulas marginais conspícuas, estrias inconspícuas. Medidas: 13,2-15,6 $\mu \mathrm{m}$ compr., 1,3-2,3 $\mu \mathrm{m}$ larg., fíbulas 19-20 em $10 \mu \mathrm{m}$.

Trata-se de uma espécie com circunscrição problemática em função do amplo espectro de variação morfológica e diversidade genética (Trobajo et al. 2009). Nitzschia palea vem sendo identificada pela forma valvar lanceolada, extremidades apicais subcapitadas e estrias inconspícuas, não visíveis ao M.O. (Kociolek 2011). Os materiais examinados assemelham-se aos materiais reportados para os Estados Unidos (Kociolek 2011), sobretudo em relação aos valores métricos e formas valvares.

A espécie já foi reportada para o Estado do Paraná (Tremarim et al. 2009). Para a área de estudo, foi citada para o Reservatório de Rosana (Bicudo et al. 1993) e para o rio Tibagi (Bittencourt-Oliveira 2002). Neste estudo, distribuiu-se nos reservatórios de Jurumirim, Chavantes, Salto Grande, Capivara e Rosana, ocorrendo em $57 \%$ das estações de amostragem (tabela 1).

Material examinado: BRASIL. São PAUlo: rio Paranapanema, Reservatório de Jurumirim, sedimento, 24-XI-2006, L. Fontana s.n. (SP390882); Divisa PARANÁ/São PaUlo: rio Paranapanema, Reservatório de Chavantes, sedimento, 19-IV-2006, L. Fontana s.n. (SP390885, SP390886); Reservatório de Salto Grande, sedimento, 17-I-2006, L. Fontana s.n. (SP390887); Reservatório de Capivara, sedimento, 17-I-2006, L. Fontana s.n. (SP390890, SP390891, SP390892); Reservatório de Rosana, sedimento, 8-VI-2006, L. Fontana s.n. (SP390894).

\section{Hantzschia Grunow}

Hantzschia amphioxys (Ehrenberg) Grunow, Kongl. Svensk. Vetensk.-Akad. Handl. 17: 103. 1880. Figura 59-60

Valvas lineares a linear-lanceoladas, constritas na região mediana da margem fibulada, extremidades capitadas; fíbulas marginais conspícuas, estrias delicadas, de difícil visualização. Medidas: 25,2-30 $\mu \mathrm{m}$ compr., 3,2-4,2 $\mu \mathrm{m}$ larg., fíbulas 11-14 em $10 \mu \mathrm{m}$.

Não há ilustração disponível do material-tipo desta espécie (Cleve \& Grunow 1880). Os materiais examinados assemelham-se à população de diatomáceas registrada na Europa (Krammer \& Lange-Bertalot 1988), bem como observada na Planície Costeira do Rio Grande do Sul (Bes \& Torgan 2010), apesar da última apresentar maior largura valvar $(6-9 \mu \mathrm{m})$.

Trata-se de espécie com ampla ocorrência no Brasil, principalmente nos Estados do Paraná e São Paulo (Eskinazi-Leça et al. 2012). Na área de estudo, já foi reportada para o Reservatório de Rosana (Bicudo et al. 1993) e, no presente, distribuiu-se nos reservatórios de Jurumirim, Chavantes, Salto Grande, Capivara e Rosana, ocorrendo em 57\% das estações de amostragem (tabela 1).

Material examinado: BRASIL. São PAUlo: rio Paranapanema, Reservatório de Jurumirim, sedimento, 24-XI-2006, L. Fontana s.n. (SP390882); Divisa PARANÁ/SÃo PAUlo: rio Paranapanema, Reservatório de Chavantes, sedimento, 19-IV-2006, L. Fontana s.n. (SP390885, SP390886); Reservatório de Salto Grande, sedimento, 17-I-2006, L. Fontana s.n. (SP390887); Reservatório de Capivara, sedimento, 
17-I-2006, L. Fontana s.n. (SP390890, SP390891, SP390892); Reservatório de Rosana, sedimento, 8-VI-2006, L. Fontana s.n. (SP390894).

\section{RHOPALODIALES \\ RHOPALODIACEAE \\ Rhopalodia Müller}

\section{Rhopalodia sp.}

Figura 61

Valvas dorsiventrais, margem dorsal convexa, margem ventral côncava, estrias paralelas e radiadas em direção às extremidades. Medidas: 12,6-21,9 $\mu \mathrm{m}$ compr., 8,0-9,2 $\mu \mathrm{m}$ larg., estrias $5 \mathrm{em} 10 \mu \mathrm{m}$.

Assemelha-se a Rhopalodia musculus (Kützing) O. Müller, principalmente pela presença de margem ventral fortemente convexa, dimensões valvares (comprimento e largura), diferindo, todavia, por apresentar menor número de estrias em $10 \mu \mathrm{m}$ (Kociolek 2011). A identificação em nível específico não foi possível devido aos materiais incompletos observados (valvas quebradas). Contudo, consideramos importante manter o registro desse gênero na flora, principalmente, por ser pouco documentado em águas brasileiras e, sobretudo, para a área do presente estudo. Ao que tudo indica, trata-se da primeira ocorrência do táxon para a bacia do Paranapanema, ocorrendo apenas na região lacustre do Reservatório de Rosana, em 7\% das estações de amostragem (tabela 1).

Material examinado: BRASIL. Divisa PARANÁ/São PAULO: rio Paranapanema, Reservatório de Rosana, sedimento, 8-VI-2006, L. Fontana s.n. (SP390894).

Considerações Finais - A avaliação conjunta de todas as classes de diatomáceas nas represas em cascata do rio Paranapanema (tabela 2) permitiu observar que: a) a Classe Bacillariophyceae foi a mais bem representada em riqueza, contribuindo com 6 a 20 táxons (média de 13 espécies) por estação de amostragem, seguida por Coscinodiscophyceae e Fragilariophyceae, respectivamente com média de três (1-4) e duas espécies (0-4) por estação de amostragem; b) maior riqueza de espécie ocorreu no primeiro reservatório da série em cascata (Jurumirim), muito provavelmente, devido à grande complexidade deste sistema, que, conforme Henry et al. (2006), exibe conformação espacial dendrítica, com muitas lagoas marginais e elevado tempo de residência da água (334 dias) o que fornece um ambiente bastante heterogêneo para o desenvolvimento de diversas espécies; c) no Reservatório de Capivara houve tendência de maior riqueza de espécie na estação de amostragem próxima do rio Tibagi (estação 11), o que pode ser explicado por este tributário funcionar como fonte de espécies planctônicas (inoculo de populações) para o reservatório, conforme já documentado em literatura para o fitoplâncton (Bittencourt-Oliveira 2002) e zooplâncton (Nogueira et al. 2005).

O presente estudo acresce 44 espécies e táxons infraespecíficos aos 13 inicialmente reportados por Fontana \& Bicudo (2009). Desses 44 táxons, 23 $(52,3 \%)$ representam novas citações para a bacia do Paranapanema, quatro táxons $(9,1 \%)$ para o Estado de São Paulo (Eunotia tridentula var. tridentula, Eunotia canicula, Gyrosigma nodiferum, Geissleria aikenensis), e dois (4,5\%) para o Estado do Paraná (Eunotia canicula e Cymbella tropica). Duas espécies (Cocconeis placentula e Eunotia canicula) apresentaram ampla distribuição, ocorrendo em todos os reservatórios, exceto em Rosana (último da série em cascata). Contrapondo, Rhopalodia sp. e Gomphonema subtile apresentaram distribuição mais restrita, ocorrendo apenas no Reservatório de Rosana e, ainda, Cymbopleura naviculiformis e Geissleria aikenensis

Tabela 2. Riqueza de diatomáceas nas estações de amostragem dos reservatórios em cascata do rio Paranapanema, SP/PR, Brasil. Fonte: Fontana \& Bicudo (2009) e dados obtidos neste estudo.

Table 2. Diatoms richness at the sampling sites of the cascade reservoirs of the Paranapanema River São Paulo and Paraná States, Brazil. Source: Fontana \& Bicudo (2009) and this study.

\begin{tabular}{|c|c|c|c|c|c|c|c|c|c|c|c|c|c|c|}
\hline \multirow{2}{*}{$\begin{array}{l}\text { Classes / Reservatórios } \\
\text { Estações }\end{array}$} & \multicolumn{3}{|c|}{ Jurumirim } & \multicolumn{3}{|c|}{ Chavantes } & \multicolumn{3}{|c|}{ Salto Grande } & \multicolumn{3}{|c|}{ Capivara } & \multicolumn{2}{|c|}{ Rosana } \\
\hline & 1 & 2 & 3 & 4 & 5 & 6 & 7 & 8 & 9 & 10 & 11 & 12 & 13 & 14 \\
\hline (*)Coscinodiscophyceae & 3 & 2 & 4 & 1 & 4 & 4 & 3 & 2 & 4 & 4 & 3 & 4 & 2 & 2 \\
\hline (*)Fragilariophyceae & 4 & 2 & 3 & 0 & 3 & 2 & 0 & 3 & 2 & 0 & 3 & 0 & 1 & 1 \\
\hline Bacillariophyceae & 16 & 20 & 20 & 6 & 7 & 11 & 10 & 10 & 9 & 12 & 18 & 9 & 11 & 13 \\
\hline Total & 23 & 24 & 27 & 7 & 14 & 17 & 13 & 15 & 15 & 16 & 24 & 13 & 14 & 16 \\
\hline
\end{tabular}

(*) Dados extraídos de Fontana \& Bicudo (2009) 
apenas na região à montante dos reservatórios de Capivara e Jurumirim, respectivamente.

O rio Paranapanema, com seus 929 km de extensão, ainda permanece pouco conhecido quanto à flora de diatomáceas. Nesse sentido, destaca-se a importância da análise do compartimento sedimentar, pois permite uma análise temporal e espacialmente integrada, rica em informações sobre a biodiversidade local. Assim, o presente estudo amplia substancialmente o conhecimento da biodiversidade de diatomáceas dos reservatórios em cascata do rio Paranapanema, podendo, auxiliar futuros estudos na bacia do Paranapanema com enfoque na biodiversidade, ecologia e conservação, bem como, de forma mais abrangente, os estudos em sistemas de reservatórios em cascata no país.

\section{Agradecimentos}

Os autores agradecem ao Prof. Dr. Marcos Gomes Nogueira e ao Prof. Raoul Henry, do Departamento de Zoologia da Universidade Estadual Paulista, Botucatu, pelo inestimável auxílio nas coletas e a "Duke Energy International", pela autorização das coletas. Agradecem, ainda, à Fundação de Amparo à Pesquisa do Estado de São Paulo (FAPESP) pela bolsa em nível de Mestrado concedida à primeira Autora (Processo 05/57399-6) e ao Conselho Nacional de Desenvolvimento Científico e Tecnológico pela bolsa concedida a DCB (Processo 305072/2009-9).

\section{Literatura citada}

Agostinho, A.A., Vazzoler, A.E.A.M. \& Thomaz, S.M. 1995. The high river Paraná basin: Limnological and ichthyological aspects. In: J.G. Tundisi, C.E.M. Bicudo \& T. Matsumura-Tundisi (eds.). Limnology in Brazil. ABC/SBL, Rio de Janeiro, pp. 59-103.

Barker, P.A., Pates, J.M., Payne, R.J. \& Healey, R.M. 2005. Changing nutrient levels in Grasmere, English Lake District, during recent centuries. Freshwater Biology 50: 1971-1981.

Battarbee, R.W. 1986. Diatoms analysis. In: B.E. Berglund (ed.). Handbook of Holocene Palaeohydrology. Wiley John \& Sons, New York, pp. 527-570.

Behnke, A., Friedl, T., Chepurnov, V.A. \& Mann, D.G. 2004. Reproductive compatibility and rDNA sequence Analyses in the Sellaphora pupula species complex (Bacillariophyta). Journal of Phycology 40: 193-208.

Bennion, H. 1995. Surface-sediment diatom assemblages in shallow, artificial, enriched ponds and implications for reconstructing trophic status. Diatom Research 10: 1-19.
Bere, T. \& Tundisi, J.G. 2010. Epipsammic diatoms in streams influenced by urban pollution, São Carlos, SP, Brasil. Brazilian Journal Biology 70: 921-930.

Bertolli, L.M., Tremarin, P.I. \& Ludwig, T.A.V. 2010. Diatomáceas perifíticas em Polygonum hydropiperoides Michaux, Reservatório do Passaúna, Região Metropolitana de Curitiba, Paraná, Brasil. Acta Botanica Brasilica 24: 1065-1081.

Bes, D. \& Torgan, L.C. 2010. O gênero Hantzschia Grunow (Nitzschiaceae, Bacillariophyta) em ambientes lacustres na Planície Costeira do Rio Grande do Sul, Brasil. Acta Botanica Brasilica 24: 146-152.

Bicca, A.B., Torgan, L.C. \& Santos, C.B. 2011. Eunotiaceae (Eunotiales, Bacillariophyta) em ambientes lacustres na Planície Costeira do Sul do Brasil. Revista Brasileira de Botânica 34: 1-19.

Bicudo, C.E.M., Morandi, L.L., Araújo, A., Carneiro, L.A. \& Bicudo, D.C. 2009. Algas. In: M.I.M.S. Lopes, M. Kirisaura \& M.M.R.F. Melo (eds.). Patrimônio da Reserva Biológica do Alto da Serra de Paranapiacaba: a Antiga Estação Biológica do Alto da Serra. Instituto de Botânica, São Paulo, pp. 187-212.

Bicudo, D.C., Bicudo, C.E.M., Castro, A.A.J. \& PicelliVicentim, M.M. 1993. Diatomáceas (Bacillariophyceae) do trecho a represar do Rio Paranapanema (Usina Hidrelétrica de Rosana), Estado de São Paulo, Brasil. Hoehnea 20: 47-68.

Bittencourt-Oliveira, M.C. 2002. A comunidade fitoplanctônica do rio Tibagi: uma abordagem preliminar de sua diversidade. In: M.E. Medri (ed.). A bacia do rio Tibagi. UEL, Londrina, pp. 373-402.

Brassac, N.M. \& Ludwig, T.A.V. 2005. Amphipleuraceae e Diploneidaceae (Bacillariophyceae) da bacia do rio Iguaçu, PR, Brasil. Acta Botanica Brasilica 19: 359-368.

Brassac, N.M. \& Ludwig, T.A.V. 2006. Diatomáceas da Bacia do Rio Iguaçu, Paraná, Brasil: Pinnularia e Caloneis. Hoehnea 33: 127-142.

Brassac, N.M., Atab, D.R., Landucci, M., Visinoni, N.D. \& Ludwig, T.A.V. 1999. Diatomáceas cêntricas de rios de região de abrangência da usina hidrelétrica de Salto Caxias, PR (Bacia do Iguaçu). Acta Botanica Brasilica 13: 277-289.

Carneiro, L.A. 2003. Ordem Achnanthales (Bacillariophyceae) de águas doces do Estado de São Paulo: levantamento florístico. Dissertação de Mestrado, Instituto de Botânica, São Paulo.

Cetto, J.M., Leandrini, J.A., Felisberto, S.A. \& Rodrigues, L. 2004. Comunidades de algas perifíticas no Reservatório de Iraí, Estado do Paraná, Brasil. Acta Scientarum Biology Science 26: 1-7.

Cleve, P.T. \& Grunow, A. 1880. Beiträge zur Kenntnis der artischen Diatomeen. Kogliga Svenska vetenskapsacademie handlingar 4: 1-255. 
Costa-Böddeker, S., Bennion, H., Jesus, T.A., Albuquerque, A.L.S., Figueira, R.C.L. \& Bicudo, D.C. 2012. Paleolimnologically inferred eutrophication of a shallow tropical urban reservoir, southeast Brazil. Journal of Paleolimnology 48: 751-766.

Dawson, P.A. 1972. Observations on the stucture of some forms of Gomphonema parvulum Kütz. 1. Morphology based on light microscopy and transmission and scanning electron microscopy. British Phycological Journal 7: 255-271.

Ehrenberg, C.G. 1843. Mittheilungen über 2 neue asiatische Lager fossiler Infusorien-Erden aus dem russischen Trans-Kaukasien (Grusien) und Sibirien. Bericht über die zur Bekanntmachung geeigneten Verhandlungen der Königlich-Preussischen Akademie der Wissenschaften zu Berlin. pp. 43-49.

Eskinazi-Leça, E., Cunha, M.G.G.S., Santiago, M.F., Borges, G.C.P., Lima, J.C., Silva, M.H., Menezes, M., Ferreira, L.C., Aquino, E. 2012. Bacillariophyceae. In: R.C. Forzza, A. Costa, B.M.T. Walter, J.R. Pirani, M.P. Morim, L.P. Queiroz, G. Martinelli, A.L. Peixoto, M.A.N. Coelho, J.F.A. Baumgratz, J.R. Stehmann, L.G. Lohmann, M. Hopkins. Lista de Espécies da Flora do Brasil. Jardim Botânico do Rio de Janeiro, Rio de Janeiro. http://floradobrasil.jbrj.gov.br/2012/FB098055 (acesso em 03.07.2012).

Faria, de M.D., Tremarin, P.I. \& Ludwig, T.A.V. 2010. Diatomáceas perifíticas da Represa Itaqui, São José dos Pinhais, Paraná: Fragilariales, Eunotiales, Achnanthales e Gomphonema Ehrenberg. Biota Neotropica 10: 415-427.

Felisberto, S.A. \& Rodrigues, L. 2005. Periphytic community of reservoirs cascade in the Paranapanema river, Brazil. Acta Scientarum Biology Science 27: 215-223.

Ferrari, F. \& Ludwig, T.A.V. 2007. Coscinodiscophyceae, Fragilariophyceae e Bacillariophyceae (Achnanthales) dos rios Ivaí, São João e dos Patos, bacia hidrográfica do rio Ivaí, Município de Prudentópolis, PR, Brasil. Acta Botanica Brasilica 21: 421-441.

Ferrari, F., Procopiak, L.K., Alencar, Y.B. \& Ludwig, T.A.V. 2007. Eunotiaceae (Bacillariophyceae) em Igarapés da Amazônia Central, Manaus e Presidente Figueiredo, Brasil. Acta Amazonica 37: 1-16.

Fontana, L. \& Bicudo, D.C. 2009. Diatomáceas (Bacillariophyceae) de sedimentos superficiais nos reservatórios em cascata do Rio Paranapanema (SP/ PR, Brasil): Coscinodiscophyceae \& Fragilariophyceae. Hoehnea 36: 375-386.

Furey, P. 2011. Eunotia canicula. In: Diatoms of the United States. http://westerndiatoms.colorado.edu/taxa/species/ eunotia_canicula (acesso em 18.10.2012).

Fürstenberger, C.B. \& Valente-Moreira, I.M. 2000. Diatomáceas (Bacillariophyta) perifíticas da Lagoa Tarumã, Ponta Grossa, Paraná, Brasil. Parte I. Eunotiaceae. Insula 29: 117-134.
Graça, S. da, Garcia, J.M. \& de Oliveira, P.E. 2007. Flora diatomácea moderna no Lago Estância das Águas Claras, Guarulhos (SP), Resultados qualitativos. Revista UNG - Geociências 6: 63-79.

Henry, R., Ushinohama, E. \& Ferreira, R.M.R. 2006. Fitoplâncton em três lagoas marginais ao Rio Paranapanema e em sua desembocadura no Reservatório de Jurumirim (São Paulo, Brasil) durante o período prolongado de seca. Revista Brasileira de Botânica 29: 399-414.

Hlúbiková, D., Ector, L. \& Hoffmann, L. 2011. Examination of the type material of some diatom species related to Achnanthidium minutissimum (Kütz.) Czarn. (Bacillariophyceae). Algological Studies 136-137: 19-43.

Hustedt, F. 1949. Süßwasser-Diatomeen aus dem AlbertNational Park in Belgisch- Kongo. Exploration duc Parc National Albert, mission H. Damas. 8: 1-199.

Kociolek, P. 2011. Gomphonema acuminatum. Diatoms of the United States. http://westerndiatoms.colorado. edu/taxa/species/gomphonema_acuminatum (acesso em 03.07.2012).

Krammer, K. 2002. Diatoms of Europe. Diatoms of the European Inland Waters and Comparable Habitats: Cymbella. Ruggell, A.R.G. Gantner Verlag K.G.

Krammer, K. 2003. Diatoms of Europe. Diatoms of the European Inland Waters and Comparable Habitats: Cymbopleura, Delicata, Navicymbula, Gomphocymbellopsis, Afrocymbella. Ruggell, A.R.G. Gantner Verlag K.G.

Krammer, K. \& Lange-Bertalot, H. 1988. Bacillariophyceae: Bacillariaceae, Epithemiaceae, Surerillaceae. In: H. Ettl. J. Gerloff, H. Heinig \& D. Mollenhauer. Sÿbwas Mitteleuropa. New York, Stuttgart, G. Fisher.

Krammer,K.\& Lange-Bertalot,H. 1991. Bacillariophyceae: Achnanthaceae. Kritishe Ergänzungen zu Navicula (Lineolatae) und Gomphonema. In: H. Ettl. J. Gerloff, H. Heinig \& D. Mollenhauer Sübwas. Mitteleuropa. Stuttgart \& Jena, G. Fisher.

Kulikovskiy, M., Lange-Bertalot, H., Witkowiski, A. \& Dorofeyuk, N. 2009. Morphology and Taxonomy of selected cymbelloid diatoms from a Mongolian Sphagnum ecosystem with a description of three species new to science. Fottea 9: 223-232.

Kützing, F.T. 1844. Die kieselschaligen Bacillarien oder Diatomeen. Nordhausen: zu finden bei W. Köhne 1: 152.

Lange-Bertalot, H. \& Jahn, R. 2000. On the indentity of Navicula (Frustulia) rhomboides and Frustulia saxonica. Systematics and Geography of Plants 70: 255-261.

Laux, M. \& Torgan, L.C. 2011. Diatomáceas com plastídeos no plâncton da foz dos rios do Delta Jacuí, Sul do Brasil: um complemento à taxonomia tradicional. Iheringia, Série Botânica 66: 109-132. 
Lozovei, A.L. \& Luz, E. 1976. Diptera culicidae em Curitiba e arredores. Arquivos de Biologia e Tecnologia 19: 43-83.

Lozovei, A.L. \& Shirata, M.T. 1990. Diatomáceas (Crysophyta, Bacillariophyceae) no Rio Passaúna, Curitiba, Paraná, Brasil - Levantamento qualitativo da diatomoflórula em segmento manancial. Estudos de Biologia 27: 5-56.

Ludwig, T.A.V. \& Flôres, T.L. 1995. Diatomoflórula dos rios da região a ser inundada para a construção da usina hidrelétrica de Segredo, PR. I Coscinodiscophyceae, Bacillariophyceae (Achnanthales e Eunotiales) e Fragilariophyceae (Meridium e Asterionella). Arquivos de Biologia e Tecnologia 38: 31-65.

Ludwig, T.A.V., Bigunas. P.I.T., Neiva, T.F., Coquemala, V.\& Piccinini, C. 2005. Diatomáceas (Ochrophyta) dos Lagos do Jardim Botânico. Revista do Museu Nacional do Rio de Janeiro 10: 301-323.

Mann, D.G., Thomas, S.J. \& Evans, K.M. 2008. Revision of the diatom genus Sellaphora: a first account of the large species in the British Isles. Fottea 8: 15-78.

Marquardt, G.C. 2012. A Ordem Cymbellales (Bacillariophyceae) no Estado de São Paulo: levantamento florístico. Dissertação de Mestrado, Instituto de Botânica, São Paulo.

Medlin, L.K. \& Kaczmarska, I. 2004. Evolution of the diatoms: V. Morphological and cytological support for the major clades and taxonomic revision. Phycologia 43: 245-270.

Metzeltin, D. \& Lange-Bertalot, H. 1998. Tropical Diatoms of South America, 1. Iconografia Diatomologica, Königstein, v.5, pp.1-95.

Metzeltin, D. \& Lange-Bertalot, H. 2007. Tropical Diatoms of South America II. Iconographia Diatomologica, Königstein, v.18, pp.1-877.

Metzeltin, D., Lange-Bertalot, H. \& García-Rodrigues, F. 2005. Diatoms of Uruguay, Annoted diatom micrographs. Iconografia Diatomologica, Königstein, v.15, pp.1-736.

Moreira-Filho, H. \& Mômoli, D.M. 1963. Diatomáceas do trato digestivo do Australorbis glabratus (Say, 1818). Boletim da Universidade Federal do Paraná 9: 1-7.

Moresco, C., Tremarin, P.I., Ludwig, T.A.V. \& Rodrigues, L. 2011. Diatomáceas perifíticas com diferentes ações antrópicas em Maringá, PR, Brasil. Revista Brasileira de Botânica 34: 359-373.

Moro, R.S. \& Bicudo, C.E.M. 1998. Flutuações climáticas no Pleistoceno tardio e Holoceno na lagoa Dourada, Estado do Paraná, Brasil. Acta Limnologica Brasiliensis 10: 47-58.

Moro, R.S., Garcia, E. \& Oliveira, Jr. H.F. 1994. Diatomáceas (Bacillariophyceae) da Represa Alagados, Ponta Grossa, Paraná, Brasil. Iheringia, Série Botânica 45: 5-19.
Moro L., Vasconcelos A.C., Santos F.G.A., Alves C.M., Nunes J.E.S. \& Sampaio I.B.M. 2004. Determination of the minimal representative number of microscopic fields to quantify apoptosis in canine lymph nodes. Arquivo Brasileiro de Medicina Veterinária e Zootecnia 56: 408-410.

Moura, A.N. \& Bittencourt-Oliveira, M.C. 2004. Diatoms (Bacillariophyceae) of the Tibagi River, Southern Brazil. Algological Studies 112: 73-87.

Moutinho, S.O., Garcia, M.J. \& Oliveira, P.E. 2007. Flora diatomácea do Reservatório Cabuçu, Município de Guarulhos, SP: Análise qualitativa. Revista UnG Geociências 6: 32-62.

Nogueira, M.G. 2000. Phytoplankton composition, dominance and abundance as indicators of environmental compartmentalization in Jurumirim Reservoir (Paranapanema River), São Paulo, Brazil. Hydrobiologia 431: 115-128.

Nogueira, M.G., Jorcin, A., Vianna, N.C. \& Britto, Y.C. 2005. Reservatórios em cascata e os efeitos na limnologia e organização das comunidades bióticas (fitoplâncton, zooplâncton e zoobentos) - um estudo de caso no rio Paranapanema (SP/PR). In: M.G. Nogueira, R. Henry \& A. Jorcin (eds). Ecologia de Reservatórios: Impactos Potenciais, Ações de Manejo e Sistemas em Cascata. São Carlos, Rima, pp. 83-125.

Nogueira, M.G., Ferrareze, M., Moreira, L.M. \& Gouvêa, R.M. 2010. Phytoplankton assemblages in a reservoir cascade of a large tropical subtropical river, SE, Brazil. Brazilian Journal of Biology 70: 781-793.

Oliveira, M.A., Torgan, L.C., Lobo, E.A. \& Scharzbold.A. 2001. Association of periphytic diatom species of artificial substrate in lotic environments in the Arroio Sampaio Basin, RS, Brazil: relationships with abiotic variables. Brazilian Journal of Biology 61: 523-540.

Patrick \& Reimer, C.W. 1966. The diatoms of United States. Monographs of the Academy of Natural Sciences-Philadelphia 1: 1-688.

Pavlov, A., Nakov, T. Levkov, Z. Furey, P., Lowe, R. \& Ector, L. 2009. Luticola grupcei (Bacillariophyceae). A New freshwater diatom from Mountain Baba (Macedonia) and Great Smoky Mountains National Park (U.S.A.): comparison with the type material of L. goeppertiana (Bleisch) D.G. Mann. Nova Hedwigia 89: 147-164.

Potapova, M. 2011. Navicula notha. Diatoms of the United States. http://westerndiatoms.colorado.edu/taxa/species/ navicula_notha (acesso em 04.07.2012).

Procopiak, L.K., Fernandes, L.F. \& Moreira-Filho, H. 2006. Diatomáceas (Bacillariophyceae) marinhas e estuarinas do Paraná, Sul do Brasil: Lista de espécies com ênfase em espécies nocivas. Biota Neotropica 6: $1-28$. 
Reichardt, E. 2001. Revision der Arten um Gomphonema truncatum und G. capitatum In: R. Jahn, J.P. Kociolek, A. Witkowski, P. Compère (eds.). Koenigstein, Koeltz Scientific Books, pp. 187-224.

Rocha, A.C.R. 2008. A família Pinnulariaceae (Bacillariophyceae) no Estado de São Paulo: levantamento florístico. Dissertação de Mestrado, Universidade Estadual Paulista, Rio Claro.

Rocha, A.C.R. \& Bicudo, C.E.M. 2008. Criptógamos do Parque Estadual das Fontes do Ipiranga, São Paulo, SP. Algas, 25: Bacillariophyceae (Naviculales: Pinnulariaceae). Hoehnea 35: 597-618.

Rodrigues, L. 1991. Naviculaceae (Bacillariophyceae) nas Lagoas do Horto Florestal Dr. Luis Teixeira Mendes, Município de Maringá, Paraná, Brasil. Revista Unimar 13: 259-272.

Rodrigues, L. \& Moreira-Filho, H. 1990. Diatomoflórula do Rio Tubarão, Santa Catarina, Brasil: I - Eunotiaceae Kützing e Achnanthaceae Kützing. Insula 20: 111-135.

Round, F.E., Crawford, R.M. \& Mann, D.G. 1990. The Diatoms: biology and morphology of the genera. Cambridge, Cambridge University Press.

Santos, E.M., Tremarin, P.I. \& Ludwig, T.A.V. 2011. Diatomáceas perifíticas em Potamogeton polygonus Cham. \& Schltdl.: Citações pioneiras para o Estado do Paraná. Biota Neotropica 11: 304-315.

Schmidt, A. 1874-1959. Atlas der Diatomaceen-Kunde. Leipzing., Reinsland O.R.

Silva, C.A., Train, S. \& Rodrigues, L.C. 2001. Estrutura e dinâmica da comunidade fitoplantônica a jusante e montante do Reservatório de Corumbá, Caldas Novas, Estado de Goiás, Brasil. Acta Scientiarum 23: 283-290.

Silva, C.A., Train, S. \& Rodrigues, L.C. 2005. Phytoplankton assemblages in a Brazilian cascading reservoir system. Hydrobiologia 537: 99-109.

Silva, A.M., Tavares, B., Aquino, N.F. de \& Wengrat, S. 2007. Gomphonemataceae (Bacillariophyceae) do Rio São Francisco Falso, Estado do Paraná, Brasil. Revista Brasileira de Biociências 5: 306-308.
Silva,A.M., Ludwig, T.A.V. Tremarin, P.I.\& Vercellino, I.S. 2010. Diatomáceas perifíticas em um sistema eutrófico brasileiro (Reservatório de Iraí, Estado do Paraná). Acta Botanica Brasilica 24: 997-1016.

Silva, W.J., Nogueira, I.S. \& Souza, M.G.M. 2011. Catálogo de diatomáceas da região centro-oeste brasileira. Iheringia, Série Botânica 66: 61-86.

Soares, F.S., Konoplya, B.I.B, Silva, J.F.M. da \& Andrade, S.G.T.J. 2011. Amphipleuraceae (Bacillariophyceae) do alto da bacia do Ribeirão Cambé, Londrina, Brasil. Revista Brasileira de Botânica 34: 39-49.

Souza, G.S., Koening, M.L., Leça, E.E. \& Coêlho, M. de P.C.A. 2007. Diatomáceas indicadoras de paleoambientes do Quaternário de Dois Irmãos, Recife, PE, Brasil. Acta Botanica Brasilica 21: 521-529.

Tavares, B. \& Valente-Moreira, I.M. 2000. Diatomoflórula do Lago de Cascavel, Município de Cascavel, Estado do Paraná, Brasil. Hoehnea 27: 1-24.

Torgan, L.C., Becker, V. \& Santos, C.B. 2009. Skeletonema potamos (Bacillariophyta) in Patos Lagoon, Southern Brazil: Taxonomy and distribution. Revista Peruana de Biologia 6: 93-96.

Tremarin, P.I., Ludwig, T.A.V. \& Moreira-Filho, H. 2008. Eunotia Ehrenberg (Bacillariophyceae) do Rio Guaraguaçu, litoral do Paraná, Brasil. Acta Botanica Brasilica 22: 845-862.

Tremarin, P.I., Ludwig, T.A.V., Bertolli, L.M., Faria, D.M. \& Costin, J.C. 2009. Gomphonema Ehrenberg e Gomphosphenia Lange-Bertalot (Bacillariophyceae) do Rio Maurício, Paraná, Brasil. Biota Neotropica 9: 111-130.

Trobajo, R., Clavero, E., Chepurnov, V.A., Sabbe, K., Mann, D.G., Ishihar, S. \& Cox, E.J. 2009. Morphological, genetic and mating diversity within the widespread bioindicator Nitzschia palea (Bacillariophyceae). Phycologia 48: 443-459.

Van Heurck, H. 1880-1881. Synopsis des Diatomées de Belgique. Anvers.

VanLandingham, S.L. 1967-1979. Catalogue of the fossil and recent genera and species of Diatoms and their synonym. Lehre, J. Cramer. 